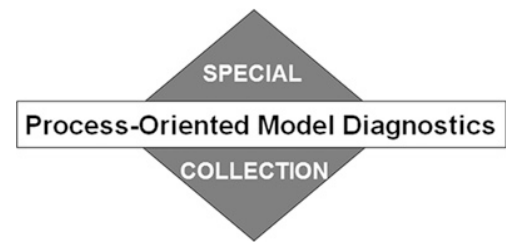

\title{
On Mapping the Diapycnal Water Mass Transformation of the Upper North Atlantic Ocean
}

\author{
XiaObiao Xu \\ Center for Ocean-Atmosphere Prediction Studies, Florida State University, Tallahassee, Florida \\ PETER B. RHINES \\ University of Washington, Seattle, Washington \\ ERIC P. CHASSIGNET \\ Center for Ocean-Atmosphere Prediction Studies, Florida State University, Tallahassee, Florida
}

(Manuscript received 31 October 2017, in final form 10 August 2018)

\begin{abstract}
Diapycnal water mass transformation is the essence behind the Atlantic meridional overturning circulation (AMOC) and the associated heat/freshwater transports. Existing studies have mostly focused on the transformation that is forced by surface buoyancy fluxes, and the role of interior mixing is much less known. This study maps the three-dimensional structure of the diapycnal transformation, both surface forced and mixing induced, using results of a high-resolution numerical model that have been shown to represent the large-scale structure of the AMOC and the North Atlantic subpolar/subtropical gyres well. The analyses show that 1) annual mean transformation takes place seamlessly from the subtropical to the subpolar North Atlantic following the surface buoyancy loss along the northward-flowing upper AMOC limb; 2) mixing, including wintertime convection and warm-season restratification by mesoscale eddies in the mixed layer and submixed layer diapycnal mixing, drives transformations of (i) Subtropical Mode Water in the southern part of the subtropical gyre and (ii) Labrador Sea Water in the Labrador Sea and on its southward path in the western Newfoundland Basin; and 3) patterns of diapycnal transformations toward lighter and denser water do not align zonally - the net three-dimensional transformation is significantly stronger than the zonally integrated, two-dimensional AMOC streamfunction $(50 \%$ in the southern subtropical North Atlantic and $60 \%$ in the western subpolar North Atlantic).
\end{abstract}

\section{Introduction}

Large-scale ocean circulation plays a fundamental role in Earth's climate by transporting heat and freshwater (or salinity anomaly) through ocean basins while mixing internally and interacting with the atmosphere. Of particular focus here is the Atlantic meridional overturning circulation (AMOC), which consists of a net northward flow of warm saline water in approximately the upper $1000 \mathrm{~m}$ overlying a net southward flow of colder fresher water. At $26.5^{\circ} \mathrm{N}$, the $\mathrm{AMOC}$ is responsible for virtually all the observed northward 1.25-PW $\left(1 \mathrm{PW}=10^{15} \mathrm{~W}\right)$ heat transport (e.g., McCarthy et al. 2015) and 30\% more than the observed southward 0.38-Sv $\left(1 \mathrm{~Sv}=10^{6} \mathrm{~m}^{3} \mathrm{~s}^{-1}\right)$ net freshwater transport (McDonagh et al. 2015) because

Corresponding author: Xiaobiao Xu, xxu@coaps.fsu.edu the subtropical gyre contributes freshwater transport northward (Xu et al. 2016). These large heat/freshwater transports result from the diapycnal transformation of the warm saline water in the northward-flowing upper limb into the colder, fresher, and denser North Atlantic Deep Water (NADW) in the southward-flowing lower limb. Thus, there is a strong need to quantify the magnitude and structure of the water mass transformation in the North Atlantic Ocean.

Part of the warm water in the upper limb of the AMOC flows across the Greenland-Scotland Ridge and is transformed into the Nordic Seas Overflow Water (NSOW) and returned to the North Atlantic (Hansen and Østerhus 2000; Saunders 2001), whereas

Publisher's Note: This article was revised on 4 October 2018 to include the designation that it belongs to the Process-Oriented Model Diagnostics special collection. 
the remainder flows around the subpolar gyre and is transformed into the Labrador Sea Water (LSW; McCartney and Talley 1982). From observations of the chlorofluorocarbons (CFCs) inventory, LeBel et al. (2008) estimated a long-term averaged NSOW and LSW formation rate of 7.9 and $11.7 \mathrm{~Sv}$, respectively. This formation rate of NSOW (including entrainment) is in reasonable agreement with the volume transports estimated from moored current-meter arrays along the western boundary of the subpolar North Atlantic: $9.0 \mathrm{~Sv}$ at $59^{\circ} \mathrm{N}$ (Bacon and Saunders 2010), 9-10 Sv at 53 $\mathrm{N}$ (Fischer et al. 2004, 2010), and $8.9 \mathrm{~Sv}$ at $43^{\circ} \mathrm{N}$ (Schott et al. 2004, 2006). The LSW formation rate of LeBel et al. (2008), however, differs from estimates listed in Table 1 of Pickart and Spall (2007), where 10 observational studies yield an average formation rate of $4.4 \mathrm{~Sv}$ with a wide range of 1-10 Sv. It is also unclear as to where and how the LSW water mass transformation takes place. LSW is observed to be formed in the central Labrador Sea by wintertime deep convection (e.g., McCartney and Talley 1982; Marshall et al. 1998) and to spread toward different regions in the subpolar and subtropical basins (e.g., Talley and McCartney 1982; Rhein et al. 2002). Based on the hydrographic and subsurface float data collected from 1990 to 1997 (a period of intense deep convection), Pickart and Spall (2007) estimated a small diapycnal transformation of $2 \mathrm{~Sv}$ across the World Ocean Circulation Experiment (WOCE) AR7W line (Fig. 1), suggesting that some of the LSW is actually formed in the Labrador Sea southeast of the AR7W line and in the southern Irminger Sea (Pickart et al. 1997, 2003a,b). More recently, von Appen et al. (2014) estimated about $3 \mathrm{~Sv}$ of intermediate water, mostly in LSW density range, from the East Greenland Spill Jet (e.g., Pickart et al. 2005) in the northern Irminger Sea.

Mapping the structure of water mass transformation requires continuous measurements of the large-scale three-dimensional circulation fields (volume transport, temperature, and salinity) with fine spatial resolution. This is challenging, and the existing studies have mostly focused on the transformation that is induced directly by surface buoyancy fluxes (surface-forced transformation hereafter), using the thermodynamic framework of Walin (1982). This framework allows the diapycnal transformation to be calculated from two-dimensional fields of surface density and air-sea buoyancy fluxes (e.g., Speer and Tziperman 1992; Speer et al. 1995; Marsh 2000; Brambilla et al. 2008; Langehaug et al. 2012; Grist et al. 2014). The spatial distribution of the surface-forced transformations in the subpolar North Atlantic was mapped by Brambilla et al. (2008). They show that areas of strong diapycnal transformation coincide with the locations of Subpolar Mode Waters (SPMW) characterized by low potential vorticity and that the transformations

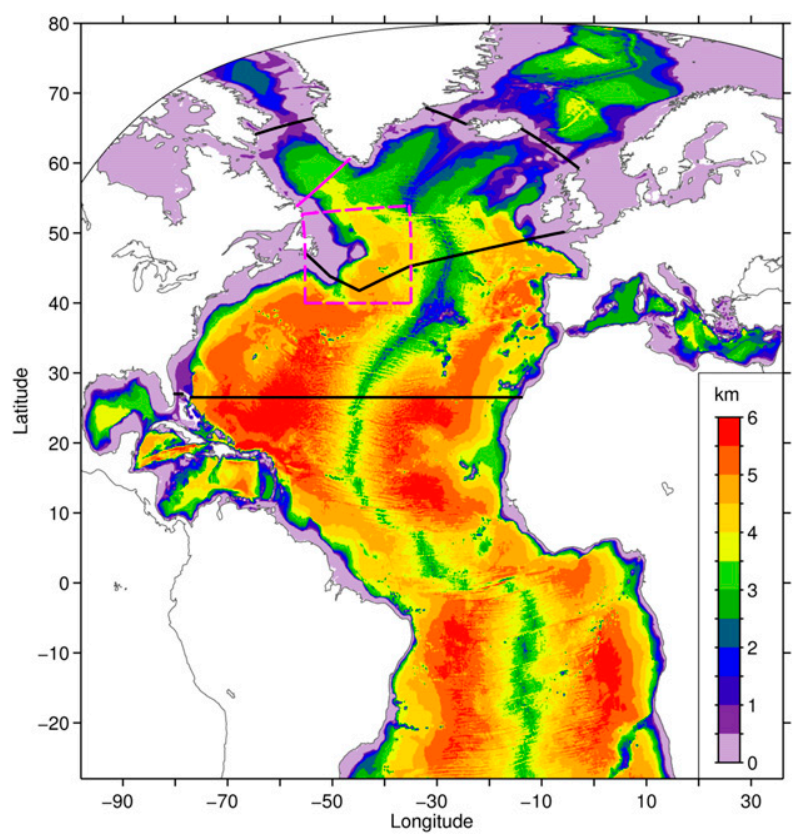

FIG. 1. Bathymetry of the model domain along with the location of key sections used in this study: the black lines from south to north are the RAPID line at $26.5^{\circ} \mathrm{N}$, the WOCE line AR19, and the Greenland-Scotland Ridge; the magenta line in the Labrador Sea is the WOCE line AR7W; the magenta box denotes the subpolar-subtropical transition region.

take place around the cyclonic subpolar gyre: from the Newfoundland Basin to the Iceland Basin, the Reykjanes Ridge, the Irminger Basin, and finally the Labrador Sea, a vivid illustration of the transformation toward LSW first described in McCartney and Talley (1982).

Surface buoyancy fluxes, however, do not account for all the diapycnal water mass transformation. Diapycnal transformations can also occur across steep isopycnal slopes in the mixed layer via lateral diffusive fluxes, especially at high latitudes (Marshall et al. 1999). Furthermore, using hydrographic data and inverse model calculations, Lumpkin et al. (2008) suggested that much of the LSW exported southward across $48^{\circ} \mathrm{N}$ is generated within the subpolar North Atlantic by diapycnal mixing rather than directly by air-sea fluxes. Eddy-permitting model results of Marsh et al. (2005, their Fig. 9) also show strong mixing-induced water mass transformation in the North Atlantic, often in opposite direction to the surface-forced transformation. These studies only considered the integrated transformation over large areas, and the spatial distribution remains largely unknown.

The AMOC is normally evaluated by integrating the meridional velocity east-west, along either constant depth or constant potential density (or neutral density) levels, and much of the discussion of ocean circulation is focused on the two-dimensional (latitude vs depth or density) 
AMOC streamfunction and its maximum amplitude. However, these two-dimensional patterns disguise the threedimensional structures of circulation and do not represent the spatially complex nature of internal subsurface turbulent mixing and diapycnal velocity. The main goal of this paper is to map the spatial structure of the diapycnal transformation of the surface waters toward denser waters in the North Atlantic that is associated with the upper limb of the AMOC, specifically, where the diapycnal transformation takes place and where the mixing-induced transformation becomes important. The results are based on an eddying Atlantic simulation that has been shown to represent well the structure of the large-scale AMOC and the subtropical/subpolar gyre circulations (e.g., Xu et al. 2016).

The paper is organized as follows: Section 2 describes the model simulation and the diagnostics of the diapycnal water mass transformation. The area-integrated water mass transformation is discussed in section 3 . Then in section 4, we discuss the spatial structure of the transformation in the subtropical and subpolar regions of the North Atlantic Ocean. The results are summarized and discussed in section 5.

\section{Numerical simulation and diapycnal transformation diagnostics}

\section{a. Numerical simulation}

The numerical simulation is performed using the Hybrid Coordinate Ocean Model (HYCOM; Bleck 2002; Chassignet et al. 2003; Halliwell 2004), and the model configuration is described in Xu et al. (2016) and references therein. The model domain covers the North and equatorial Atlantic (Fig. 1) with a horizontal resolution of $1 / 12^{\circ}$ and a vertical resolution of 64 layers in potential density referenced to $2000 \mathrm{~m}\left(\sigma_{2} ; \mathrm{kg} \mathrm{m}^{-3}\right)$. The southern and northern boundaries are closed, and the modeled potential temperature $\theta$ and salinity $S$ within a buffer zone of $3^{\circ}$ from these two boundaries are restored toward the ocean climatology. The simulation is integrated using monthly climatological forcing from the 40-yr European Centre for Medium-Range Weather Forecasts Re-Analysis (ERA-40; Uppala et al. 2005) and 3-hourly wind anomalies for 2003, a year with neutral North Atlantic Oscillation. The anomalies are based on the Fleet Numerical Meteorology and Oceanography Center $0.5^{\circ}$ Navy Operational Global Atmospheric Prediction System (NOGAPS; Rosmond et al. 2002). The surface heat flux forcing includes the shortwave and longwave radiations that are directly from ERA-40 and the latent and sensible heat fluxes that are calculated using the model sea surface temperature (SST) and bulk formulas of Kara et al. (2005). The surface freshwater forcing, prescribed as a salinity flux, includes evaporation, precipitation, and river runoffs. In addition, the model sea surface salinity (SSS) is restored toward ocean climatology with a restoring strength of $15 \mathrm{~m}$ per 30 days. A simple thermodynamic model (Semtner 1976) is used for sea ice. The modeled winter sea ice coverage is similar to that observed in the Nordic seas, the Baffin Bay, and the Hudson Bay but is less extensive in the western shelf of the Irminger and Labrador Seas. The thermodynamic model, however, cannot simulate the freshwater input to the Labrador Sea owing to melting of sea ice transported from the north. These limitations can impact the heat and freshwater fluxes in the region. The simulation is integrated for 20 years, and the diagnostics are performed for the last five years of the integration, which is representative of the modeled mean circulation after spinup.

The vertical coordinate of HYCOM is isopycnal in the stratified open ocean, and it makes a dynamically smooth and time-dependent transition to terrain following in shallow coastal regions and fixed pressure levels in the surface mixed layer and/or unstratified seas (Chassignet et al. 2006). In doing this, the model combines the advantages of the different coordinate types in simulating coastal and open ocean circulation simultaneously. In the high latitudes (north of $\sim 55^{\circ} \mathrm{N}$ ), the vertical coordinate is mostly $z$ coordinate in the upper $1000 \mathrm{~m}$ because of the small vertical density gradient. As in Chassignet and Garraffo (2001), Xu et al. (2010), and Chassignet and Xu (2017), the horizontal viscosity operator for momentum is a combination of Laplacian $A_{2}=\max \left(A, 0.05 \Delta x^{2} \times\right.$ deformation tensor $)$ and biharmonic $A_{4}=V_{4} \Delta x^{3}$ with $A=20 \mathrm{~m}^{2} \mathrm{~s}^{-1}$ and $V_{4}=1 \mathrm{~cm} \mathrm{~s}^{-1}$. The lateral diffusion for temperature and salinity is harmonic and varies as a function of grid size $A_{H}=V_{H} \Delta x$, with $V_{H}=0.5 \mathrm{~cm} \mathrm{~s}^{-1}$. This gives values for $A_{H}$ of approximately $30-40 \mathrm{~m}^{2} \mathrm{~s}^{-1}$ for a grid size of $6-8 \mathrm{~km}$. The vertical mixing is parameterized using $K$-profile parameterization (KPP; Large et al. 1994). Below the mixed layer, the vertical mixing in KPP consists of three terms, representing 1) background diffusivity due to unresolved internal wave breaking $\left(0.1 \mathrm{~cm}^{2} \mathrm{~s}^{-1}\right.$ for tracers), 2) local Richardson number instability due to resolved shear (a function of gradient Richardson number), and 3) double diffusion (functions of double diffusion density ratio). For the majority of the ocean interior below and across the base of mixed layer depth, the vertical mixing coefficient is the small background diffusivity and the corresponding diapycnal transformation is small. The performance of KPP in HYCOM within a coarseresolution framework was examined in Halliwell (2004). One should point out that the parameterization of internal wave breaking used here has no vertical/horizontal variations and that a better parameterization with a more realistic, inhomogeneous pattern [see MacKinnon et al. (2017) 
for a review] may lead to a different picture of water mass transformation in the interior.

\section{b. Diagnosis method}

For a given density surface $\sigma$ and an enclosed area, the total diapycnal transformation $F_{T}(\sigma)$ that takes place in the numerical model can be computed as in Smith et al. (2000) as the difference between 1) the net horizontal transport $F_{N}(\sigma)$ into the area between the sea surface and the density surface $\sigma$ and 2) the change of volume above the density surface over time $(\Delta V / \Delta t)$ :

$$
F_{T}(\sigma)=F_{N}(\sigma)-\Delta V / \Delta t .
$$

In the case of steady state (no volume change), the net horizontal transport $F_{N}(\sigma)$ is identical to the total water mass transformation $F_{T}(\sigma)$ that takes place in the enclosed area.

The surface-forced transformation $F_{S}(\sigma)$ is computed separately using the thermodynamic method (Walin 1982; Speer and Tziperman 1992), in which the diapycnal transformation, or the transport across an outcropping density surface, is equivalent to the transformation of the surface density from one to another via surface density flux $D$. Thus, for a given density surface $\sigma$ and an enclosed area $A, F_{S}(\sigma)$ is the integration of surface density flux $D$ over the area $d A$ where the surface density is close to $\sigma$ :

$$
F_{S}(\sigma)=\frac{1}{\Delta \sigma} \int D \delta(\Delta \sigma) d A
$$

in which $\delta$ is a boxcar function that equals 1 if the surface density is within the range of $\sigma \pm \Delta \sigma / 2$ and 0 otherwise. The $\Delta \sigma$ is a small density variation set at $0.03 \mathrm{~kg} \mathrm{~m}^{-3}$. The area-integrated transformation $F_{S}$ for the subtropical/ subpolar region is not sensitive to the choice of $\Delta \sigma$ and is nearly identical for $\Delta \sigma$ values of $0.02-0.15 \mathrm{~kg} \mathrm{~m}^{-3}$. Larger values do, however, introduce some spatial smoothing, hence the $0.03 \mathrm{~kg} \mathrm{~m}^{-3}$ value. The density flux $D\left(\mathrm{~kg} \mathrm{~m}^{-2} \mathrm{~s}^{-1}\right)$, or the local rate of surface-forced water mass transformation, is

$$
D=\alpha C_{p}^{-1} Q_{H}-\beta Q_{S}
$$

in which $C_{p}$ is specific heat capacity of water (3996 $\mathrm{J} \mathrm{kg}^{-1} \mathrm{~K}^{-1}$ ); $\alpha$ and $\beta$ are the thermal expansion and haline contraction coefficients, respectively; and $Q_{H}\left(\mathrm{~W} \mathrm{~m}^{-2}\right)$ and $Q_{S}\left(\mathrm{~kg} \mathrm{~m}^{-2} \mathrm{~s}^{-1}\right)$ are net heat and salinity flux into the ocean, respectively.

The difference between the total and the surfaceforced transformations, $F_{T}(\sigma)-F_{S}(\sigma)$, is interpreted as the transformation induced by interior mixing $F_{I}(\sigma)$. Although "interior" is used to differentiate from surface-forced transformation $F_{S}(\sigma)$, it should be stated that $F_{I}(\sigma)$ includes all the transformations that are not due to air-sea buoyancy fluxes. Mostly, it is the transformation due to lateral mixing within the wintertime mixed layer depth. The model allows solar radiation to penetrate below the surface, and this effect is not included in the $F_{S}$ calculation in (2). This could impact the results in areas where the surface mixed layer is shallow since a warming to the water below the mixed layer could be falsely attributed to mixing instead of surface-forced transformation.

\section{Area-integrated diapycnal transformation}

In this section, we focus on the area-integrated diapycnal water mass transformation to provide a large-scale view of the transformation associated with the meridional overturning circulation in the North Atlantic.

\section{a. Meridional overturning streamfunction and diapycnal transformation}

The AMOC is usually displayed as a streamfunction defined as the zonally integrated meridional transport above a constant depth $z$ or density surface $\sigma$, defined as

$$
\begin{aligned}
& \psi_{z}(y, z)=\overline{\iint_{z^{\prime} \leq z} v\left(x^{\prime}, y, z^{\prime}, t\right) d z^{\prime} d x^{\prime}} \quad \text { and } \\
& \psi_{\sigma}(y, z)=\overline{\iint_{\sigma^{\prime} \leq \sigma} v\left(x^{\prime}, y, z^{\prime}, t\right) d z^{\prime} d x^{\prime}}
\end{aligned}
$$

where $v$ is the meridional velocity, and the overbar denotes a 5-yr average. Throughout this study, $\sigma$ is defined as the potential density referenced to $2000 \mathrm{~m}$ (i.e., $\sigma_{2}$ ). Figure 2a shows the modeled 5-yr mean meridional overturning streamfunction $\psi_{\sigma}$. The density axis is nonlinear to illustrate the details of the NADW, which has a relatively narrow density range of $36.75-37.10 \mathrm{~kg} \mathrm{~m}^{-3}$. Note also that north of $47^{\circ} \mathrm{N}$, the streamfunction is calculated along the model curvilinear grid line, and the latitude represents the zonal average of the model section across the Atlantic basin. The basin-scale positive streamlines describe the primary AMOC, with lighter water flowing northward and denser water returning southward. In the subtropical and subpolar North Atlantic, two additional sub-basin-scale overturning cells are present. These localized cells do not appear in the overturning streamfunction $\psi_{z}$. In Fig. 3 , the streamfunction $\psi_{\sigma}$ is compared to $\psi_{z}$ by displaying it as a function of depth (instead of density), that is, projection of the streamfunction on zonally averaged depth of each density surface at each latitude (e.g., Döös and Webb 1994; McIntosh and McDougall 1996). The difference between $\psi_{\sigma}$ and $\psi_{z}$ is due to the fact that the density surfaces slope from west to east. Thus, integrating the northward and 


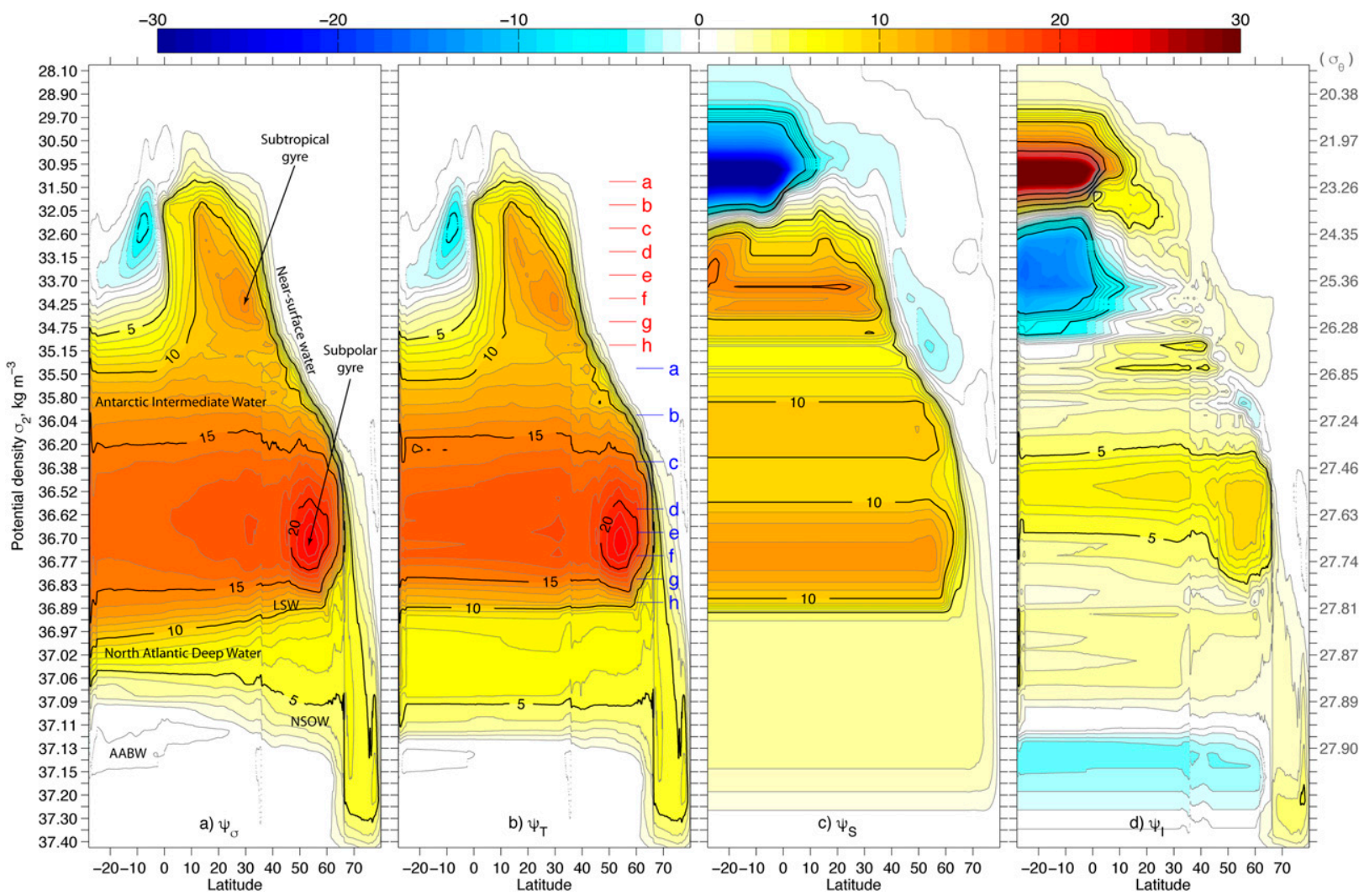

FIG. 2. Modeled 5-yr (a) mean meridional overturning streamfunction $\psi_{\sigma}$ and (b) area-integrated total $\psi_{T}$, (c) surface-forced $\psi_{S}$, and (d) interior-mixing-induced $\psi_{I}$ diapycnal water mass transformations as a function of latitude and density $\sigma_{2}$ (corresponding potential density $\sigma_{\theta}$ on the the right axis). Contour interval is $1 \mathrm{~Sv}$; note the contours of $\psi_{S}$ and $\psi_{I}$ do not represent streamlines because they are only one part of the diapycnal transformation. The latitude values north of $47^{\circ} \mathrm{N}$ are the zonal average of the curvilinear model grid. Red and blue lines in (b) (labeled $\mathrm{a}-\mathrm{h}$ ) denote two sets of isopycnic surfaces across which the horizontal distribution of the transformation is mapped (Figs. 6-8 and 12-14). The water masses shown are LSW, NSOW, and Antarctic Bottom Water (AABW).

southward transports that are equal on constant depth along density surfaces can result in an overturning cell in $\psi_{\sigma}$. A similar geometrical argument has been put forward to explain the Deacon cell in the Southern Ocean, which is about $15 \mathrm{~Sv}$ in $\psi_{z}$ while virtually disappearing in $\psi_{\sigma}$ (Döös and Webb 1994), although transient eddies can also play a significant role there.

The overturning streamfunction $\psi_{\sigma}$ at a given latitude represents the net transports $F_{N}$ for the area from the latitude to the northern boundary. The streamfunction $\psi_{T}$ (Fig. 2b), representing the total diapycnal transformation $F_{T}$ for the same area, is

$$
\psi_{T}=\psi_{\sigma}-\Delta V / \Delta t
$$

here, $\Delta V / \Delta t$ is the change of volume (between sea surface and the density surface $\sigma$ from the latitude to northern boundary) over the 5 years. The $\psi_{T}$ is very similar to the $\psi_{\sigma}$ except for a subtle difference in the NADW layers south of $45^{\circ} \mathrm{N}$, where the gradual merging of the streamlines in $\psi_{\sigma}$ (Fig. 2a) represents volume change or vertical displacement of the density surface, not diapycnal transformation. This result shows that, although the modeled kinetic energy is stable after spinup (5-10 years), the density field in the deep layers continues to adjust, and it will take a much longer integration for the model to reach a full equilibrium state.

The sum of the surface-forced $F_{S}$ and mixing-induced $F_{I}$ transformations for the area north of a given latitude, denoted as $\psi_{S}$ and $\psi_{I}$, respectively, are displayed in Figs. $2 \mathrm{c}$ and $2 \mathrm{~d}$ along with the $\psi_{T}$ (Fig. 2b). The modeled $\psi_{S}$ is similar to Fig. 2 of Grist et al. (2014) based on airsea fluxes from reanalysis and ocean climatology. The surface-forced transformations in the surface layer toward lighter water are particularly strong in the tropics. These strong transformations in the tropics are compensated by transformations toward denser water induced by mixing with the upwelled colder water from the northward limb of the AMOC. Thus, the net effect is that the water in the upper limb of AMOC becomes 


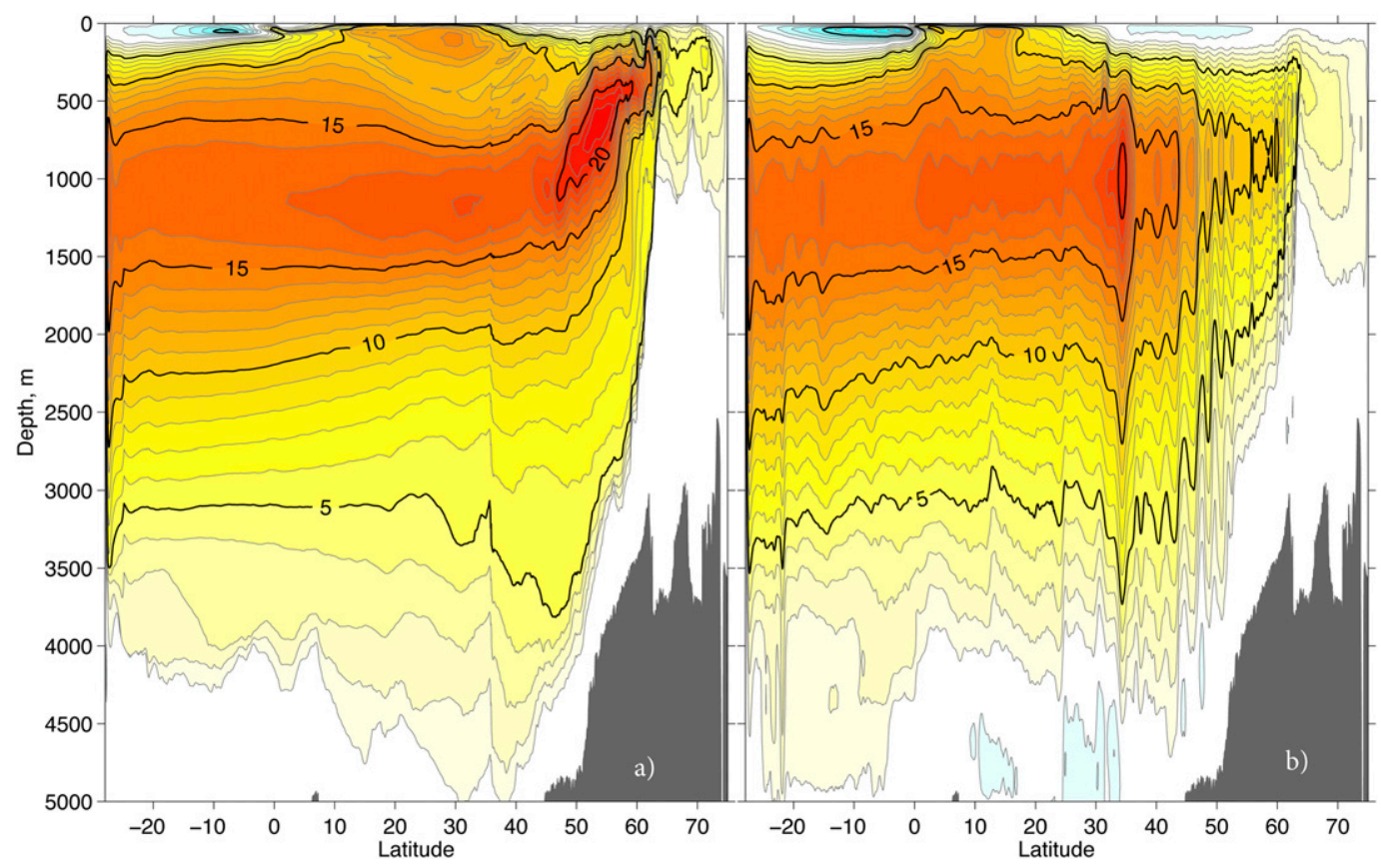

FIG. 3. A comparison of modeled 5-yr mean (a) meridional overturning streamfunction with respect to density $\psi_{\sigma}$, projected as a function of depth using the zonal mean depth of the density interface as in McIntosh and McDougall (1996) and (b) streamfunction with respect to depth $\psi_{z}$.

significantly warmer and lighter flowing across the equator. As mentioned, the solar radiation in the tropics can penetrate below the shallow mixed layer and warm the underlying colder water directly and thus change the partitioning between $F_{S}$ and $F_{I}$ (Iudicone et al. 2008). To the north, the dominant pattern in $\psi_{T}$ is that the water masses in the upper limb of the AMOC become progressively denser as they flow northward (Fig. 2b). The $\psi_{S}$ shows a similar densification of the upper-layer water masses, but the patterns are "isolated" compared to the seamless $\psi_{T}$, because surface-forced transformation only impacts the surface mixed layer (note that $\psi_{S}$ and $\psi_{I}$ represent only one part of the diapycnal transformation and cannot be used to track water mass pathways by themselves). Mixing contributes transformation toward denser water near $60^{\circ} \mathrm{N}$ and toward lighter water near $45^{\circ} \mathrm{N}$; farther north near $65^{\circ} \mathrm{N}$, entrainment mixing with the warmer ambient water transforms the very cold NSOW source toward lighter overflow water (Fig. 2d).

\section{b. Regional diapycnal transformation of the subtropical and subpolar North Atlantic}

To obtain a more quantitative measure of the water mass transformation in the North Atlantic, we calculate the water mass transformations in two regions: one from $26.5^{\circ} \mathrm{N}$ to the WOCE line AR19 (near $48^{\circ} \mathrm{N}$ ) and the other from the AR19 to the Greenland-Scotland Ridge (see Fig. 1 for location), representing the subtropical and subpolar North Atlantic, respectively. The net transports $F_{N}$ and the corresponding water mass transformations $\left(F_{T}, F_{S}, F_{I}\right)$ for these two regions are compared in Fig. 4. The results show that about $12-\mathrm{Sv}$ water in the $\sigma_{2}$ range of $31-33.7 \mathrm{~kg} \mathrm{~m}^{-3}$ is transformed into denser water of $33.7-35.5 \mathrm{~kg} \mathrm{~m}^{-3}$ in the subtropical region (Fig. 4a). This transformed water flows farther north into the subpolar region and is transformed there into even denser water of $36.68-36.96 \mathrm{~kg} \mathrm{~m}^{-3}$ (Fig. 4b). These transformations are to a large degree surface forced (green lines). The mixing-induced transformation $F_{I}$ is generally weaker but significant too (orange). In both the subtropical and subpolar regions, the surface-forced transformation $F_{S}$ extends to a denser water than the total transformation $F_{T}$. This is due to wintertime convection, which deepens the mixed layer toward high densities, whereas the interior mixing with ambient water lowers the density for the transformed water. In the subpolar North Atlantic (Fig. 4b), there is a transformation of $\sim 5 \mathrm{~Sv}$ toward lighter water across $\sigma_{2}$ of $37.13 \mathrm{~kg} \mathrm{~m}^{-3}$, induced by submixed layer entrainment mixing of the dense NSOW source water with the ambient water (see also Fig. 2).

Seasonal variation of the net transport streamfunction and the corresponding water mass transformations are illustrated in Fig. 5. In both the subtropical and subpolar regions, the seasonal variability is small for the net transports $F_{N}$ but strong for the total water mass 

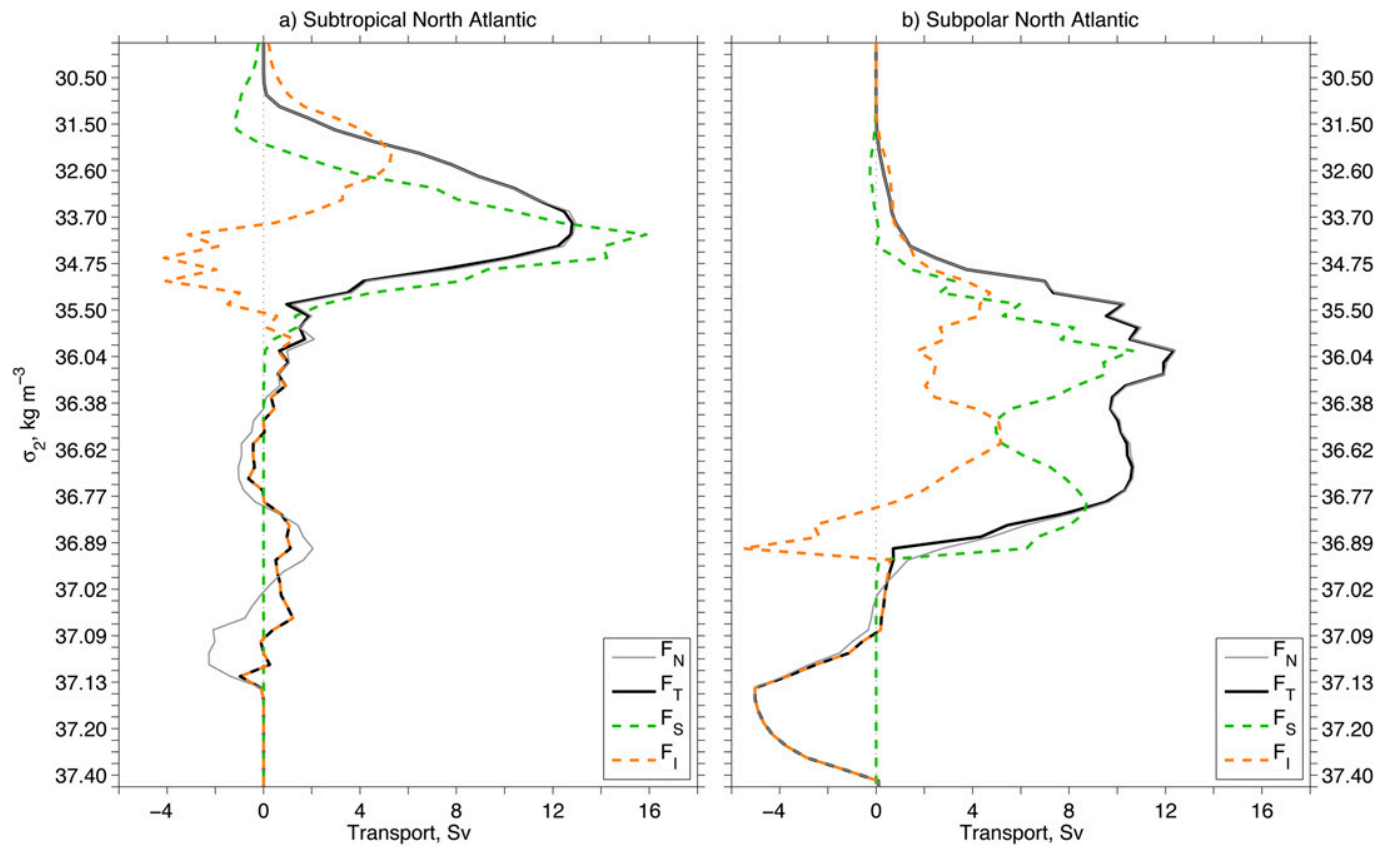

FIG. 4. Modeled 5-yr mean net horizontal transports $F_{N}$ and the total $F_{T}$, surface-forced $F_{S}$, and interiormixing-induced $F_{I}$ water mass transformations for (a) the subtropical region from $26.5^{\circ} \mathrm{N}$ to the WOCE line AR19 and (b) the subpolar region from AR19 to the Greenland-Scotland Ridge (see Fig. 1 for section locations). Positive values (Sv) in $F_{T}$ indicate transformations toward denser water. The $F_{T}$ in the subtropical plot shows transformation toward denser water across density surface near $33.7 \mathrm{~kg} \mathrm{~m}^{-3}$; the subpolar plot shows transformations toward denser water across $36.68 \mathrm{~kg} \mathrm{~m}^{-3}$ and toward lighter water across $37.14 \mathrm{~kg} \mathrm{~m}^{-3}$. Both $F_{S}$ and $F_{I}$ are significant.

transformations $F_{T}$ (Figs. 5a,b and 5e,f): The magnitude of the total transformation $F_{T}$ in winter/summer is 4-6 times higher than the annual mean $F_{N}$. Thus, while the $F_{N}$ and $F_{T}$ are approximately the same on an annual mean basis (Fig. 4), they differ significantly on a seasonal scale because of the large volume change: the dense water accumulates in winter and drains out in summer. The large seasonal volume change of upper-ocean water masses in the model is similar to observations as presented in Evans et al. (2017). Their results also show that the interannual fluctuations of the upper-ocean volume budget of the subtropical gyre are primarily set adiabatically by the variability of meridional transport at $26^{\circ}$ and $45^{\circ} \mathrm{N}$, whereas the (diabatic) air-sea fluxes have a minimal effect. The total $F_{T}$ and surface-forced $F_{S}$ transformations are qualitatively similar in both regions (Figs. 5b,c and 5f,g). The similarity suggests that the surface buoyancy fluxes do explain a significant part of diapycnal transformations in the upper North Atlantic and that the Walin (1982) framework is useful in estimating the large-scale total transformation $F_{T}$, although the mixing-induced transformations $F_{I}$ are by no means negligible, especially in the dense northern overflows but also in the upper ocean (see Figs. 5d,h).

\section{Spatial distribution of the diapycnal water mass transformation}

The previous section gave us a broad overview of the diapycnal water mass transformation in the North Atlantic. In this section, we map the 2D horizontal distributions of the modeled annual mean diapycnal transformation across a series of selected isopycnal surfaces as labeled in Fig. 2b in the subtropical and subpolar North Atlantic Ocean. The goal is to identify where the transformations take place and quantify them, with a focus on the transformations associated with the Subtropical Mode Water [STMW; also known as the Eighteen Degree Water (EDW)], the SPMW, and the LSW.

\section{a. The subtropical North Atlantic}

Figures 6, 7, and 8 map the horizontal distribution of modeled time mean total $F_{T}$, surface-forced $F_{S}$, and mixing-induced $F_{I}$ transformations per unit area, across eight density surfaces in the subtropical North Atlantic (labeled by the red letters a-h in Fig. 2b). The results are averaged over $5 \times 5$ model grid points to minimize the noise. Strong transformations toward denser water are found from the Florida Current to the Gulf Stream and 


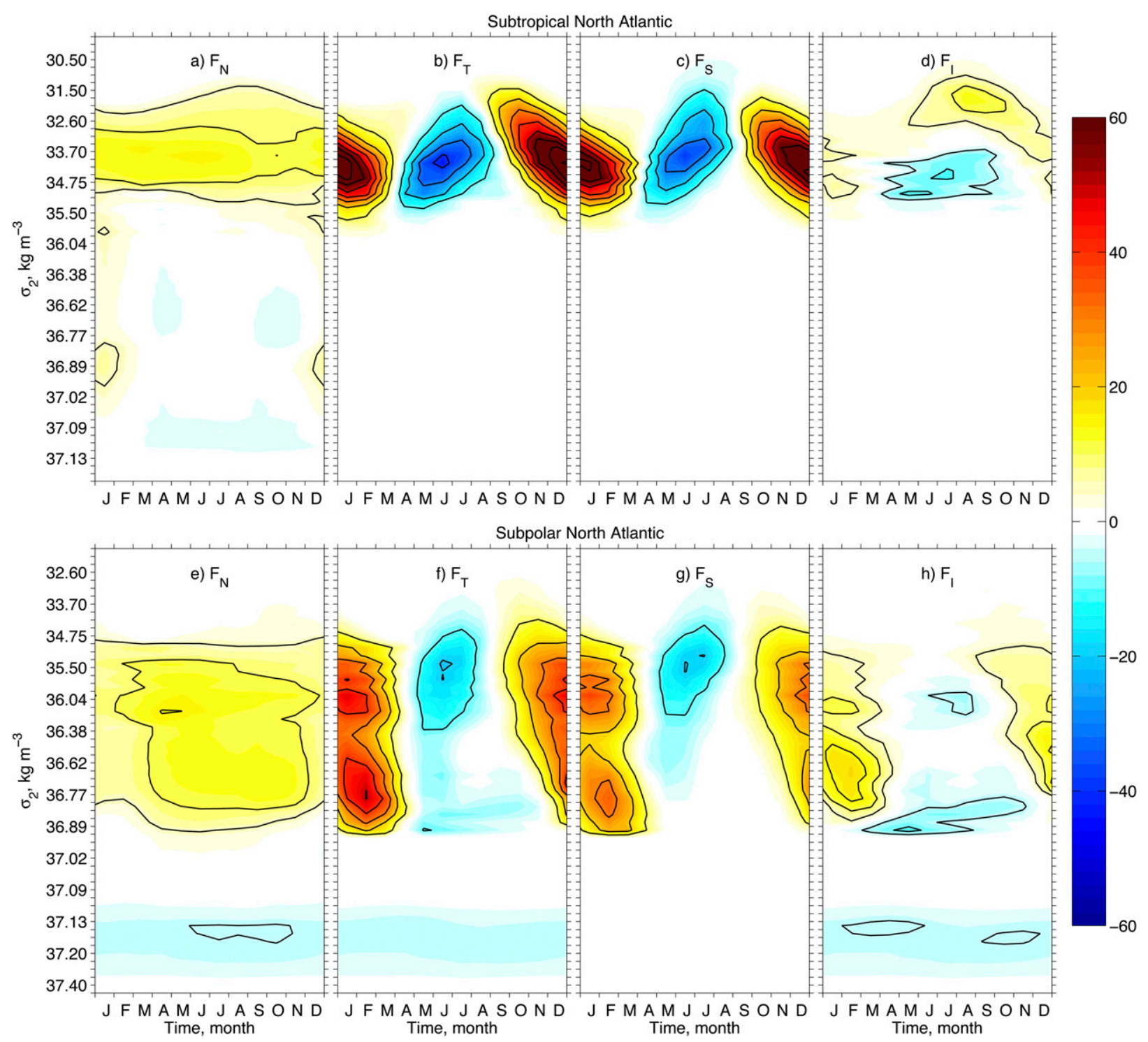

FIG. 5. Seasonal variation of the modeled net horizontal transports $F_{N}$ and the total $F_{T}$, surface-forced $F_{S}$, and interior-mixing-induced $F_{I}$ water mass transformations for (a)-(d) the subtropical region from the $26.5^{\circ} \mathrm{N}$ to the WOCE AR19 line and (e)-(h) the subpolar region from AR19 to the Greenland-Scotland Ridge (Fig. 1 for section locations). Positive values (Sv) indicate transformations toward denser water.

to the North Atlantic Current, following progressively denser isopycnals (Fig. 6). This transformation is primarily induced by surface buoyancy loss (dominated by cooling) over the Gulf Stream-North Atlantic Current system (Fig. 8). In addition to air-sea cooling of the surface, observations show that along-current wind stress induces Gulf Stream mixing where Ekman transport forces cold dense water on top of warm water (Thomas et al. 2013). In the model, the Ekman flow transports about $1.5 \mathrm{~Sv}$ near surface water southward across a latitude of $40^{\circ} \mathrm{N}$ (close to the Gulf Stream axis) between $70^{\circ}$ and $50^{\circ} \mathrm{W}$. Transformations toward denser water are also found in the open ocean over the high surface salinity area east of $50^{\circ} \mathrm{W}$ (Figs. $7 \mathrm{c}-\mathrm{f}$ ), where excessive $E-P$ also contributes to the transformation. Transformations toward lighter water are generally weaker and found mostly in three regions: in the southern Caribbean Sea (Figs. 6a-d), along the African coast (Figs. $6 \mathrm{~d}-\mathrm{f}$ ), and in a broad band across the open ocean (Figs. $6 c-h$ ). The transformation in the southern Caribbean Sea and offshore of West Africa are both associated with strong Ekman transport and upwelling that subject cold water to surface-forced warming (Fig. 7f). The transformation in the subtropical open 


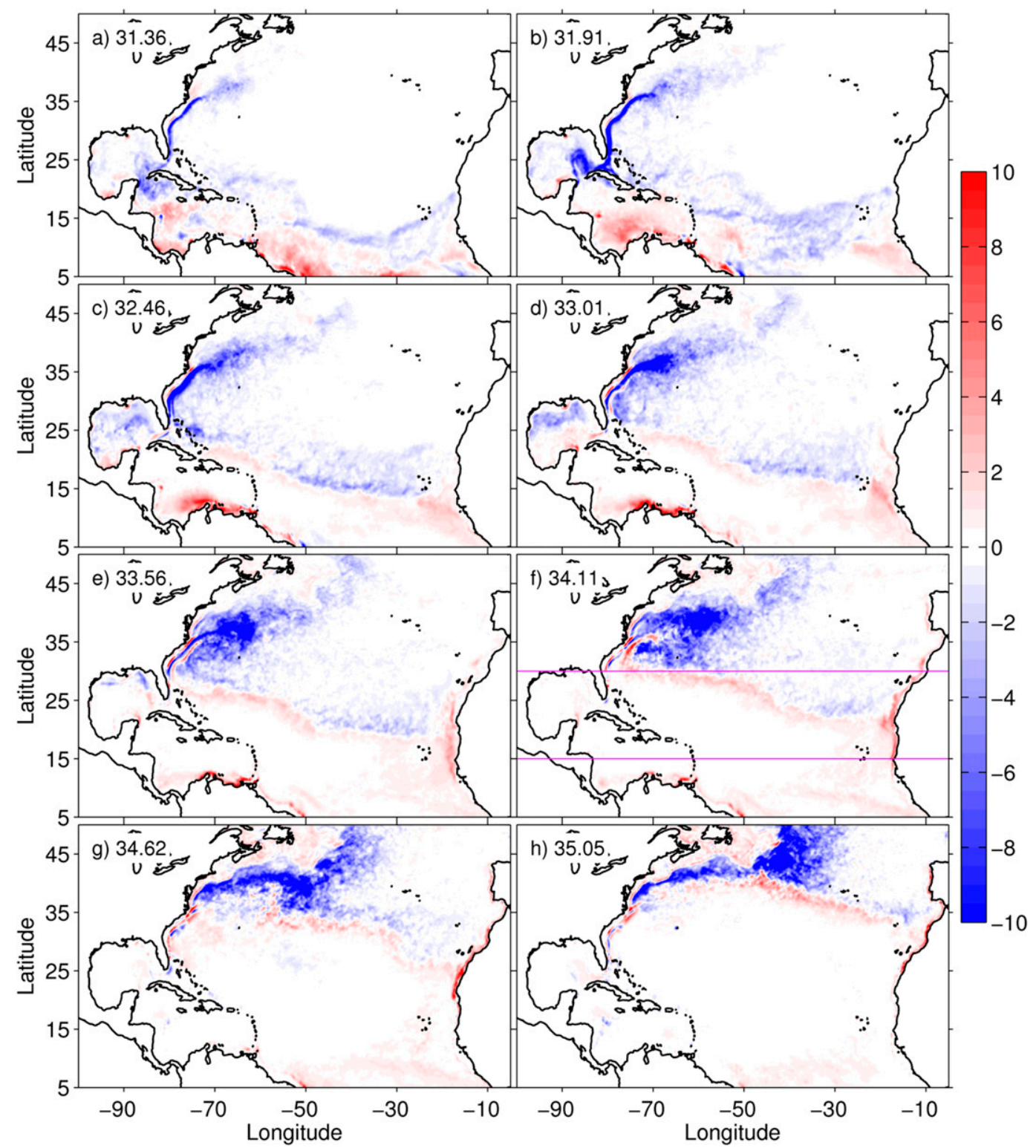

FIG. 6. Distribution of the modeled 5-yr mean, total diapycnal transformation per unit area (velocity unit $10^{-6} \mathrm{~m} \mathrm{~s}^{-1}$ ) across (a)-(h) eight density surfaces in the subtropical North Atlantic (labeled in red letters a-h in Fig. 2). The two magenta lines in (f) mark a latitude band $\left(15^{\circ}-30^{\circ} \mathrm{N}\right)$ over which the zonally accumulated water mass transformations are shown in Fig. 11.

ocean is induced by horizontal mixing in the southwestward subtropical gyre mixed layer (Figs. 8c-f and discussion below).

The density $\sigma_{2}$ surface of $34.11 \mathrm{~kg} \mathrm{~m}^{-3}$ (corresponding to the red label $\mathrm{f}$ in Fig. $2 \mathrm{~b}$ and $\sigma_{\theta}$ of $25.75 \mathrm{~kg} \mathrm{~m}^{-3}$ ) marks the center of the local cell in the subtropical North Atlantic and slightly above the STMW/EDW (characterized by $\sigma_{\theta}$ of $26.3-26.6 \mathrm{~kg} \mathrm{~m}^{-3}$ ). Thus, the transformations across this density surface toward denser/lighter waters (Figs. 6f, 7f, and 8f) connect to the formation/erosion of the STMW, respectively. Most of the modeled STMW is transformed in the Gulf Stream region and continues to flow north as it becomes denser and becomes the source for the SPMW in the subpolar region. This intricate subsurface pathway for the warm northward flow of AMOC has been suggested by Häkkinen et al. (2011) and Burkholder and Lozier (2014). Some of the STMW, however, returns southward in the subtropical gyre and is transformed toward lighter water due to horizontal mixing in the mixed layer. To illustrate this, Fig. 9 


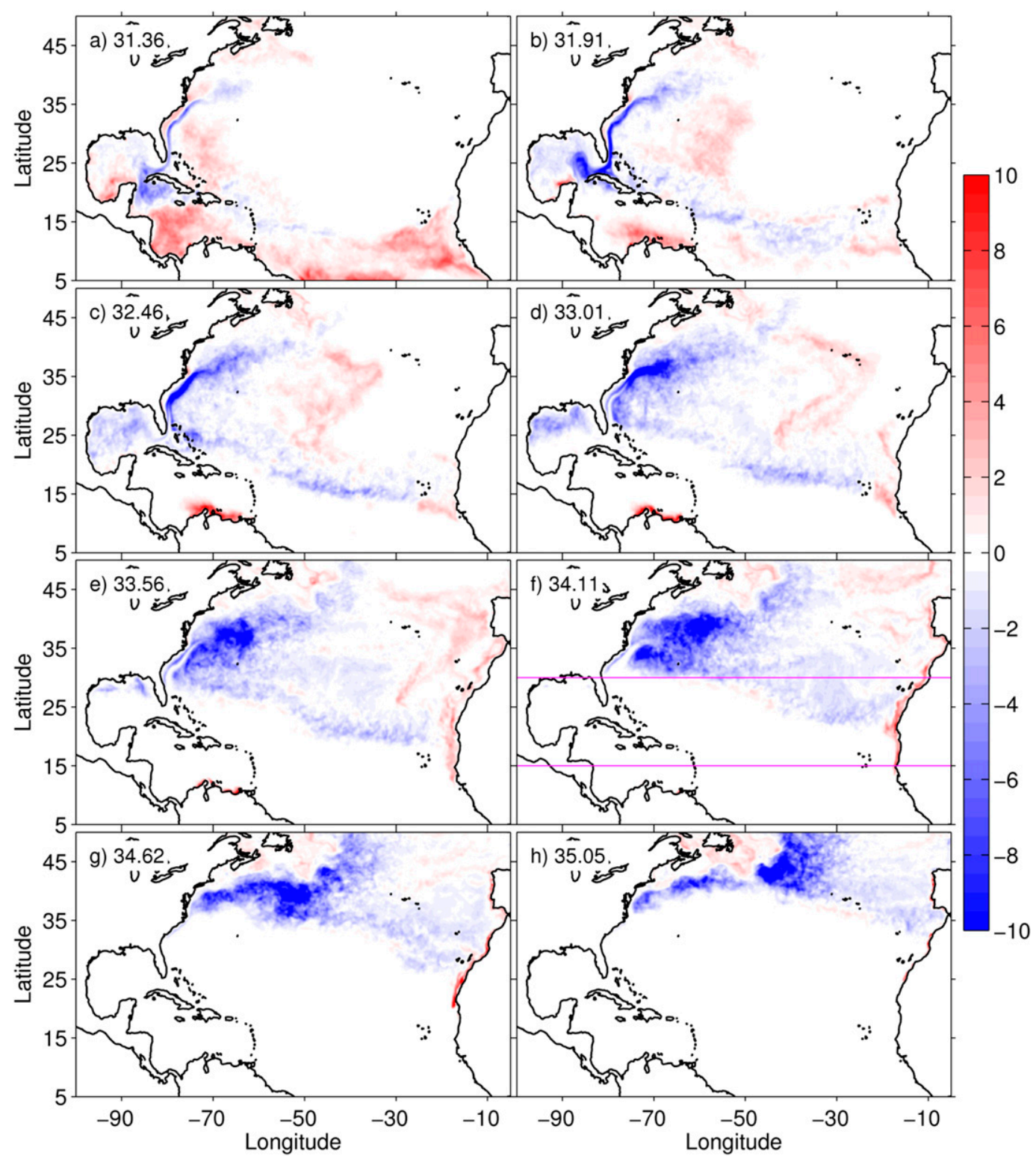

FIG. 7. As in Fig. 6, but for the surface-forced diapycnal transformation per unit area $\left(10^{-6} \mathrm{~m} \mathrm{~s}^{-1}\right)$, calculated from the local density flux $D$ in Eq. (3) and surface density.

shows the modeled time mean velocity and the magnitude of the horizontal diffusive density flux $A_{H} \nabla \rho$ for a model layer that is connected to the transformations in Fig. 8f (the broad band of transformation toward lighter water is associated with the elevated horizontal density flux). The modeled diapycnal transformation in the subtropical gyre ( $\sim 3 \mathrm{~Sv}$ in Fig. $2 b)$ is consistent with the value derived from observations across $26^{\circ} \mathrm{N}$ (Lumpkin and Speer 2003).

A meridional section view of the annual mean total transformation along $52^{\circ} \mathrm{W}$ (WOCE line A20) illustrates the relationship between transformation and mixed layer depth more clearly (Fig. 10a): The transformation toward dense water (convection) takes place mostly within the deep wintertime mixed layer depth (MLD); the transformation toward lighter water (restratification) is seen at the base of MLD, which slopes upward to the south of the Gulf Stream deep convection region. Some transformation toward lighter water is also seen below the MLD, especially in the tropics, where there is elevated interior mixing due to double diffusion with saltier water sitting above the fresh Antarctic Intermediate Water. The MLD is defined as density change from surface that is equivalent of a $0.3^{\circ} \mathrm{C}$ temperature difference. The gray 


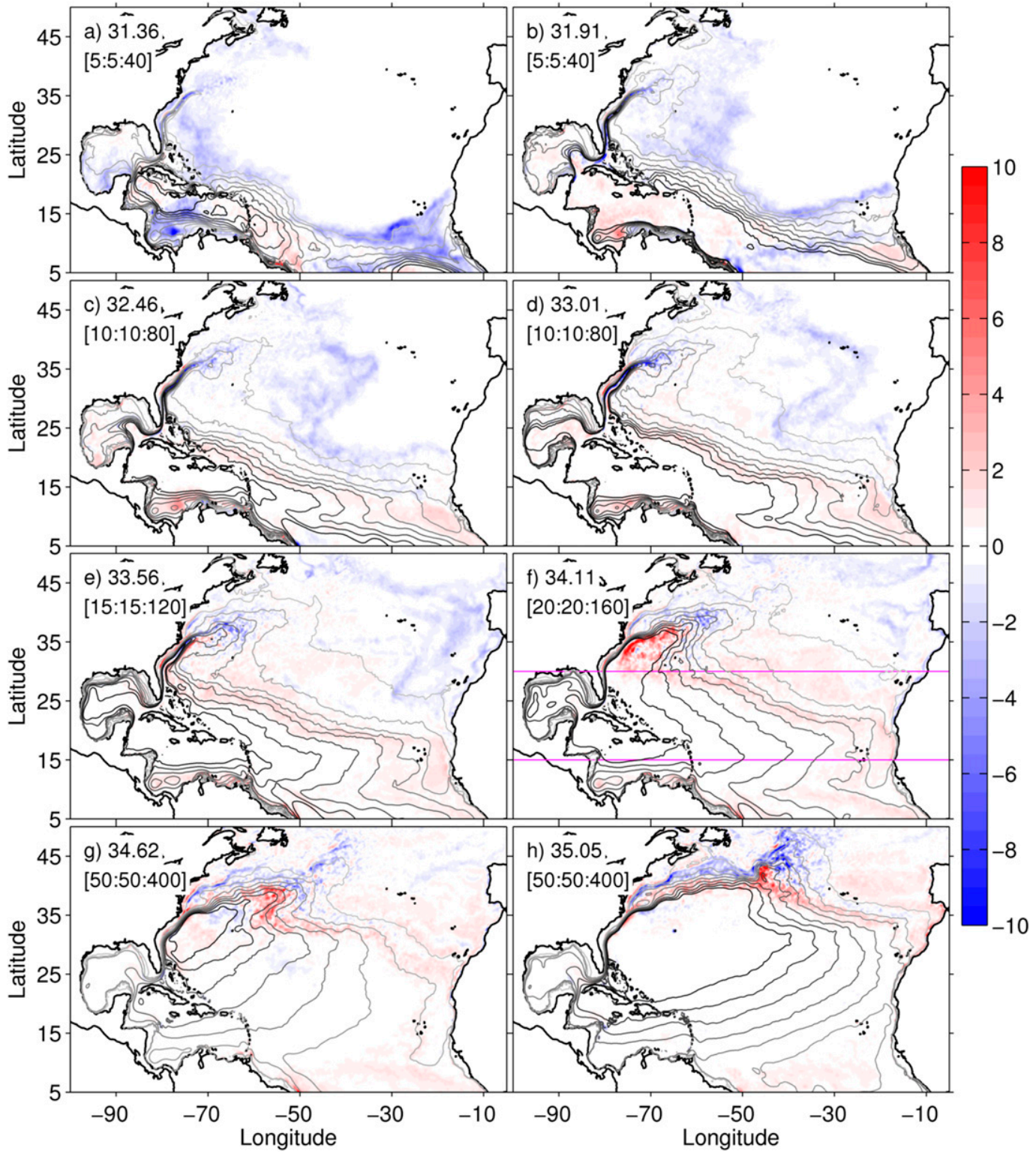

FIG. 8. As in Fig. 6, but for the interior-mixing-induced diapycnal transformation per unit area $\left(10^{-6} \mathrm{~m} \mathrm{~s}^{-1}\right)$; overlaid contours are depth of the density surfaces (bracketed numbers are the minimum, increasing interval, and maximum depths).

and black lines denote the model coordinates and the modeled isopycnal interfaces, respectively. The two differ in the MLD as the model coordinates switch from isopycnals to hybrid coordinates. Comparison between the model results and the ocean climatology of Schmidtko et al. (2013) shows that the modeled wintertime MLD and the temperature profiles agree well with the climatology (Figs. 10b,c).

The patterns of transformations toward lighter/denser water are not zonal (Fig. 6f), and consequently, the zonally integrated streamfunction in Fig. $2 b$ is not fully representative of the total diapycnal transformation in the subtropical gyre. To quantify this, we zonally integrate the transformations toward lighter and denser water separately in Fig. 11, spanning the overturning cell from $15^{\circ}$ to $30^{\circ} \mathrm{N}$ (see magenta lines in Figs. 6f, $7 \mathrm{f}$, and $8 f)$. The results show that the net $F_{T}$ transformation of 3.2 $\mathrm{Sv}$ consists of $4.7 \mathrm{~Sv}$ transformation toward lighter water minus the $1.5 \mathrm{~Sv}$ transformation toward denser water (black thin solid and dashed lines in Fig. 11, respectively). Thus, the total transformation toward lighter water that takes place within this subtropical band 

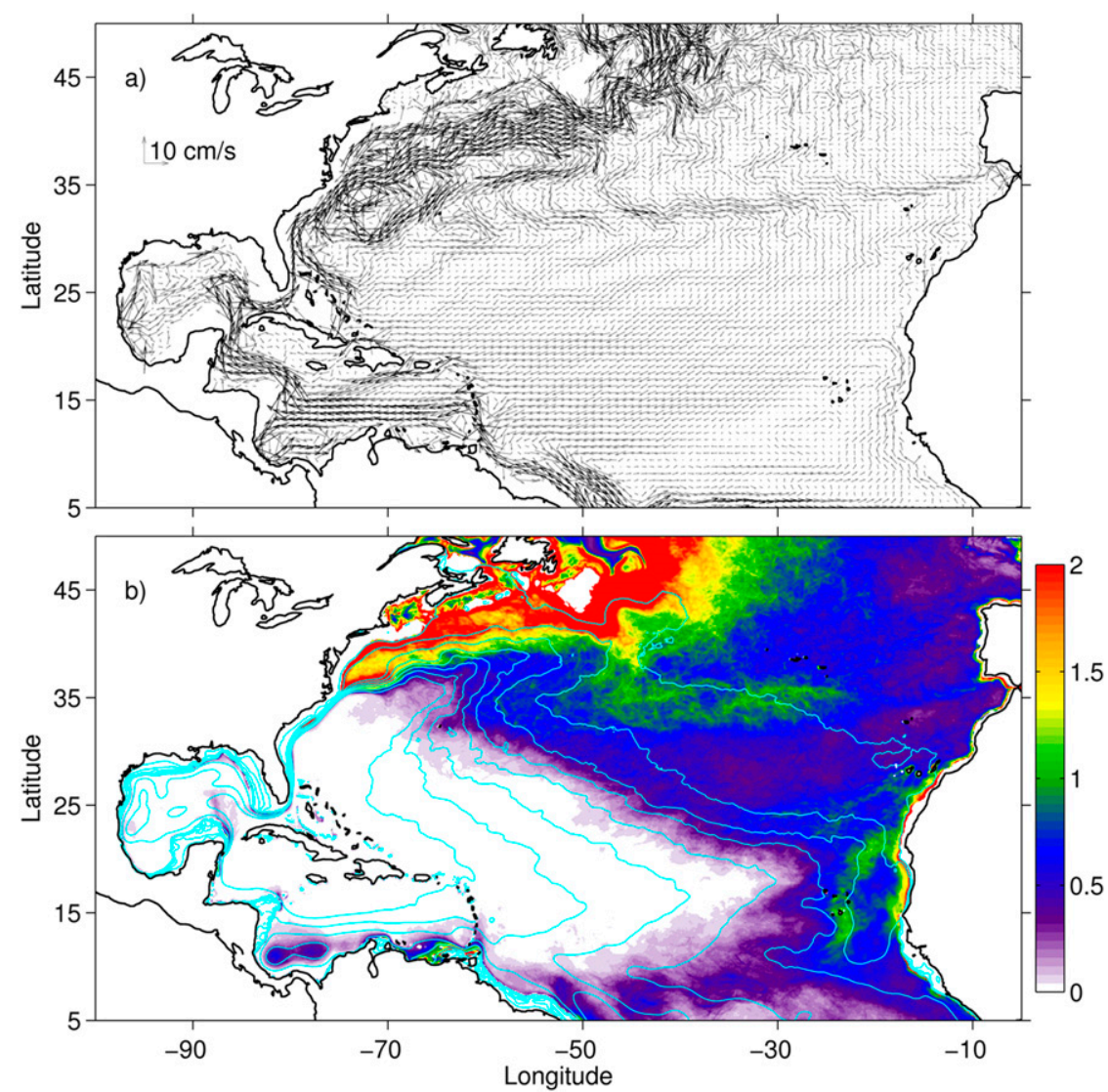

FIG. 9. (a) Modeled 5-yr mean velocity in model layer 22 associated with the broad transformation across the midocean as shown in Fig. 8f; velocity larger than $10 \mathrm{~cm} \mathrm{~s}^{-1}$ is denoted with black arrows. (b) The averaged magnitude of horizontal diffusive density $A_{H} \nabla \rho$ $\left(10^{-4} \mathrm{~kg} \mathrm{~m}^{-3} \mathrm{~m} \mathrm{~s}^{-1}\right)$ in model layer 22; overlaid cyan contours are the same depths of isopycnic surface $\left(\sigma_{2}=34.11 \mathrm{~kg} \mathrm{~m}^{-3}\right)$ as shown in Fig. 8f.

( $4.7 \mathrm{~Sv}$ ) is nearly $50 \%$ higher than the net value ( $3.2 \mathrm{~Sv}$; thick black line in Fig. 11). Decomposing $F_{T}$ into $F_{S}$ and $F_{I}$ shows that the transformation toward lighter water is mostly induced by horizontal mixing in the mixed layer (except that along the western African coast where it is surface forced), whereas the transformation toward denser water is primarily surface forced. Mixing induces a transformation of 5.2 Sv toward lighter water and $0.7 \mathrm{~Sv}$ toward denser water (orange thin solid and dashed lines), whereas the surface fluxes lead to a transformation of $1.4 \mathrm{~Sv}$ toward lighter water and $2.7 \mathrm{~Sv}$ toward denser water (green thin solid and dashed lines).

\section{b. The subpolar North Atlantic}

Similar to Figs. 6, 7, and 8, Figs. 12, 13, and 14 map the horizontal distribution of total $F_{T}$, surface-forced $F_{S}$, and interior-mixing-induced $F_{I}$ transformation per unit area, across eight isopycnals in the subpolar region (labeled by blue letters $a-h$ in Fig. 2b). As for the subtropics, the area of strong transformation toward denser water follows the gyre circulation (Fig. 10): from the North Atlantic Current that extends eastward in the polar front, to the Iceland Basin and over the Rockall Plateau, westward over the Reykjanes Ridge and around Greenland, and finally into the Labrador Sea. A significant part of this transformation is surface forced (Fig. 13), and the model results are very similar to Fig. 4 in Brambilla et al. (2008) derived from observations. However, the surface buoyancy loss does not account for all the transformation, and mixing in the mixed layer is responsible for significant transformations around the subpolar gyre (Fig. 14), particularly strong along the steep isopycnal slopes as noted by Marshall et al. (1999). Unlike the annual mean surface-forced transformations $F_{S}$ that are mostly toward denser water in the subpolar region (Fig. 11), mixing-induced transformations $F_{I}$ are in both directions (Fig. 12): toward lighter water along the deeper part of the isopycnal slope (the inshore side of the boundary current) and toward denser water along the shallow part of the isopcynal slope (the offshore side 

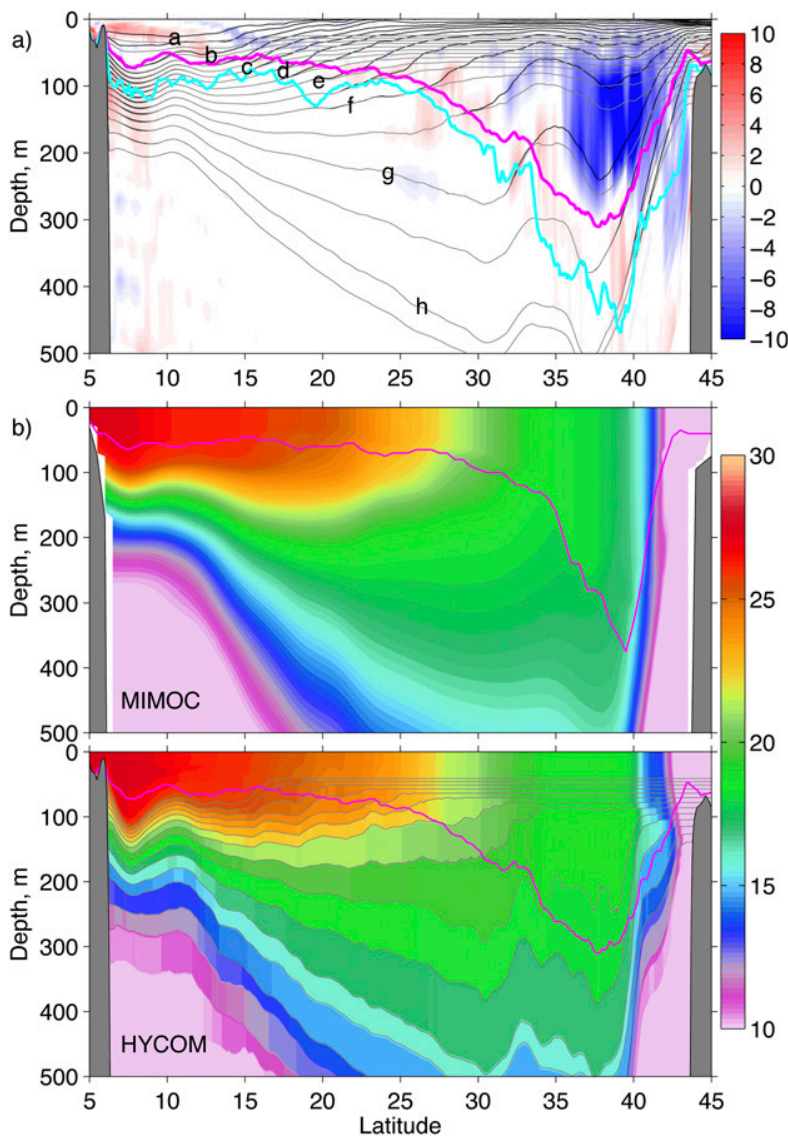

FIG. 10. (a) Modeled 5-yr mean, total diapycnal transformation $\left(10^{-6} \mathrm{~m} \mathrm{~s}^{-1}\right)$ along $52^{\circ} \mathrm{W}$. Thick magenta line is the 5 -yr averaged wintertime (March) MLD; thick cyan line is the maximum MLD; thin black lines denote the modeled mean isopycnic surfaces (letters $\mathrm{a}-\mathrm{h}$ correspond to the eight surfaces in Fig. 6); thin gray lines denote the mean locations of the model coordinates (the departure from the black lines indicates nonisopycnic conditions in the model). (b) Mean potential temperature $\left({ }^{\circ} \mathrm{C}\right.$; color shading) and MLD (magenta line) in March based on ocean climatology of Schmidtko et al. (2013) and HYCOM simulation.

of boundary current and the interior). A similar overturning circulation pattern was inferred in the Labrador Sea from tracer observations by Khatiwala et al. (2002).

As for the subtropics, the patterns of modeled total and mixing-induced transformations $F_{T}$ and $F_{I}$ do not align zonally, and thus the zonally integrated streamfunction underestimates the transformations (discussed in section $4 a$ ). To quantify this, we zonally integrate the transformations toward lighter and denser water separately in Fig. 15, across the $\sigma_{2}$ density surface of 36.815 $\left(\sigma_{\theta} \approx 27.72\right)$ over a swath of subpolar latitudes approximately $52^{\circ}-65^{\circ} \mathrm{N}$ (see magenta lines in Figs. $12 \mathrm{~g}$, $13 \mathrm{~g}$, and $14 \mathrm{~g}$ ). The net transformation $F_{T}$ across this density surface is $10 \mathrm{~Sv}$ toward denser water west of $25^{\circ} \mathrm{W}$ (including the Labrador and Irminger Seas).

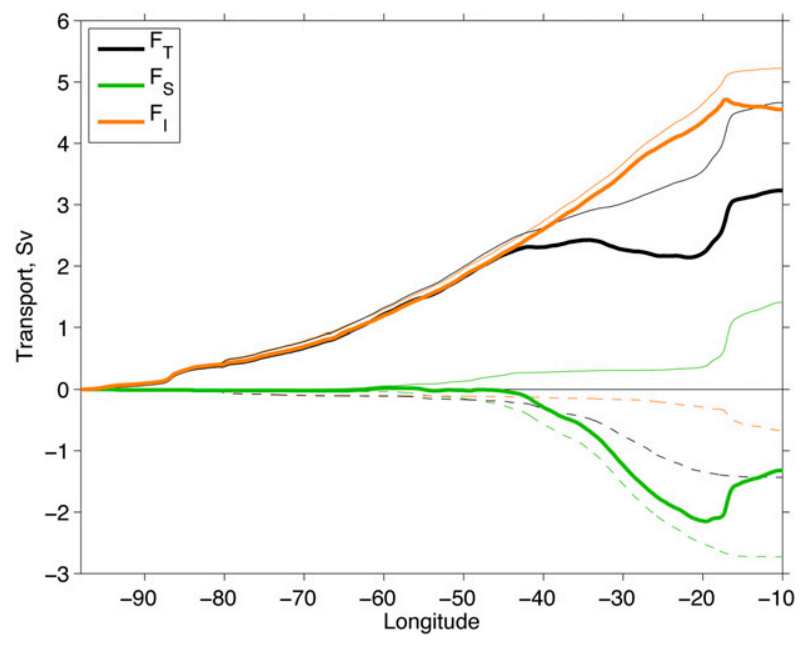

FIG. 11. Eastward accumulation of the modeled total $F_{T}$ (black), surface-forced $F_{S}$ (green), and interior-mixing-induced $F_{I}$ (orange) transformations across $\sigma_{2}$ of $34.11 \mathrm{~kg} \mathrm{~m}^{-3}$ (Figs. 6f, 7f, and $8 \mathrm{f}$ ) for the latitude band $15^{\circ}-30^{\circ} \mathrm{N}$. Thin lines denote accumulations of transformations toward lighter water (solid) and denser water (dashed) separately. Note the $F_{I}$ is largely toward lighter water owing to horizontal diffusive mixing in the wintertime mixed layer of the southwestward wind-driven subtropical gyre (Fig. 9). The $F_{\mathrm{S}}$ is primarily toward denser water corresponding to cooling and, less so, evaporative salinity increase, except near the African coast, where the upwelling cold water is warmed by air-sea flux.

This transformation is similar to the zonally integrated value in Fig. $2 b$ in this latitude range, and it can be divided into a transformation of $6.1 \mathrm{~Sv}$ toward lighter water and $16.1 \mathrm{~Sv}$ toward denser water, respectively. Thus, the transformation that is canceled out by the zonal integration $(6.1 \mathrm{~Sv})$ has an amplitude that is approximately $60 \%$ of the zonally integrated transformation in the AMOC at this level. For the same region, the mixing-induced transformation $F_{I}$ is $2 \mathrm{~Sv}$ toward denser water, consisting of transformation of $7.5 \mathrm{~Sv}$ toward lighter water and $9.5 \mathrm{~Sv}$ toward denser water, respectively (Fig. 15).

The transformation toward denser and lighter water in Figs. $14 \mathrm{~g}$ and $14 \mathrm{~h}$ is connected with the deep convection and restratification of the LSW, respectively. This (horizontal) mixing-induced transformation takes place in the mixed layer; thus, the pattern is very similar to distribution of wintertime MLD in Fig. 16a. The modeled maximum wintertime MLD in the Labrador Sea is about $2000 \mathrm{~m}$, which is deeper than the value of $1200 \mathrm{~m}$ based on the ocean climatology of Schmidtko et al. (2013); it also covers a larger area. However, a large area of MLD as deep as $2400 \mathrm{~m}$ has been observed in the Labrador Sea during the early 1990s when wintertime deep convection was particularly intense (e.g., Yashayaev 2007). The corresponding model temperature and salinity across the 


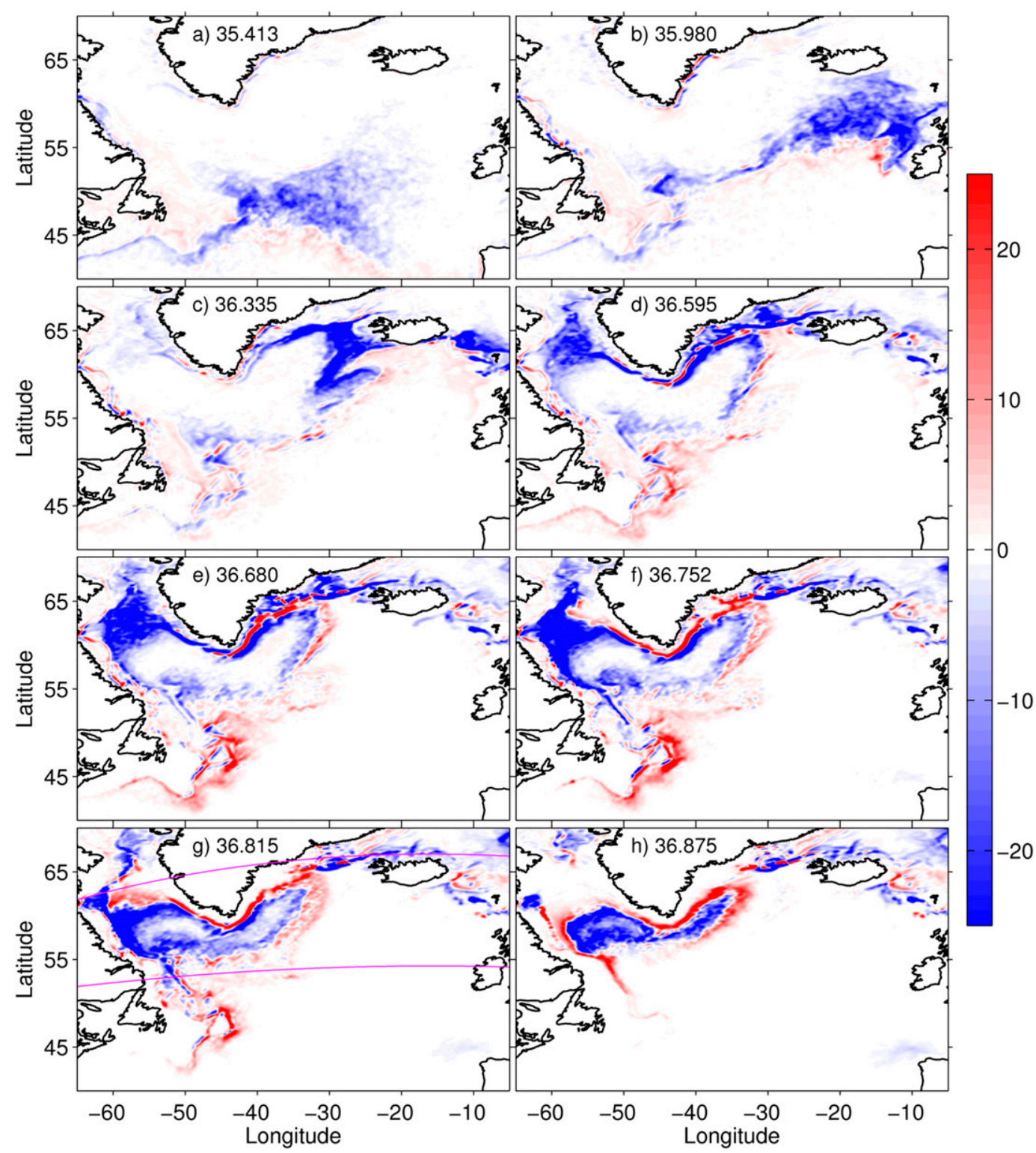

FIG. 12. Distribution of the modeled 5-yr mean, total diapycnal transformation per unit area $\left(10^{-6} \mathrm{~m} \mathrm{~s}^{-1}\right)$ across (a)-(h) eight density surfaces (blue lines a-h in Fig. 2b) in the subpolar North Atlantic. The two magenta lines in (g) mark a latitude band $\left(52^{\circ}-65^{\circ} \mathrm{N}\right)$ over which the zonally accumulated water mass transformations are shown in Fig. 15. Both surface cooling (Fig. 13) and interior mixing (Fig. 14) create ribbons of transformations toward lighter water (red) and denser water (blue) in boundary currents and fronts.

Labrador Sea along the WOCE line AR7W is shown in Figs. $16 \mathrm{~b}$ and $16 \mathrm{c}$. The modeled vertical layer structure of the water masses is consistent with the observations (Pickart et al. 2002), but the model salinity is higher than observed (by $\sim 0.04$ for LSW). This positive salinity bias exists because the model lacks the input of buoyant lowsalinity, cold shelf water that originates from the Arctic Ocean and ice-melt/runoff from Greenland and is observed in the East Greenland Coastal Current (e.g., Bacon et al. 2014). Without this upper-ocean buoyancy resistance, the Labrador Sea in model is more prone to intense deep convection (e.g., Bailey et al. 2005; Hátún et al. 2007).

Eddies play an important role in the transformations toward lighter water (Figs. 14g,h) that mostly surround the Labrador/Irminger Sea convection region, including the narrow boundary current. In the Labrador Sea interior after deep convection, eddies spawned by the baroclinic instability around the edge of newly convected dense water are one of the main mechanisms for 


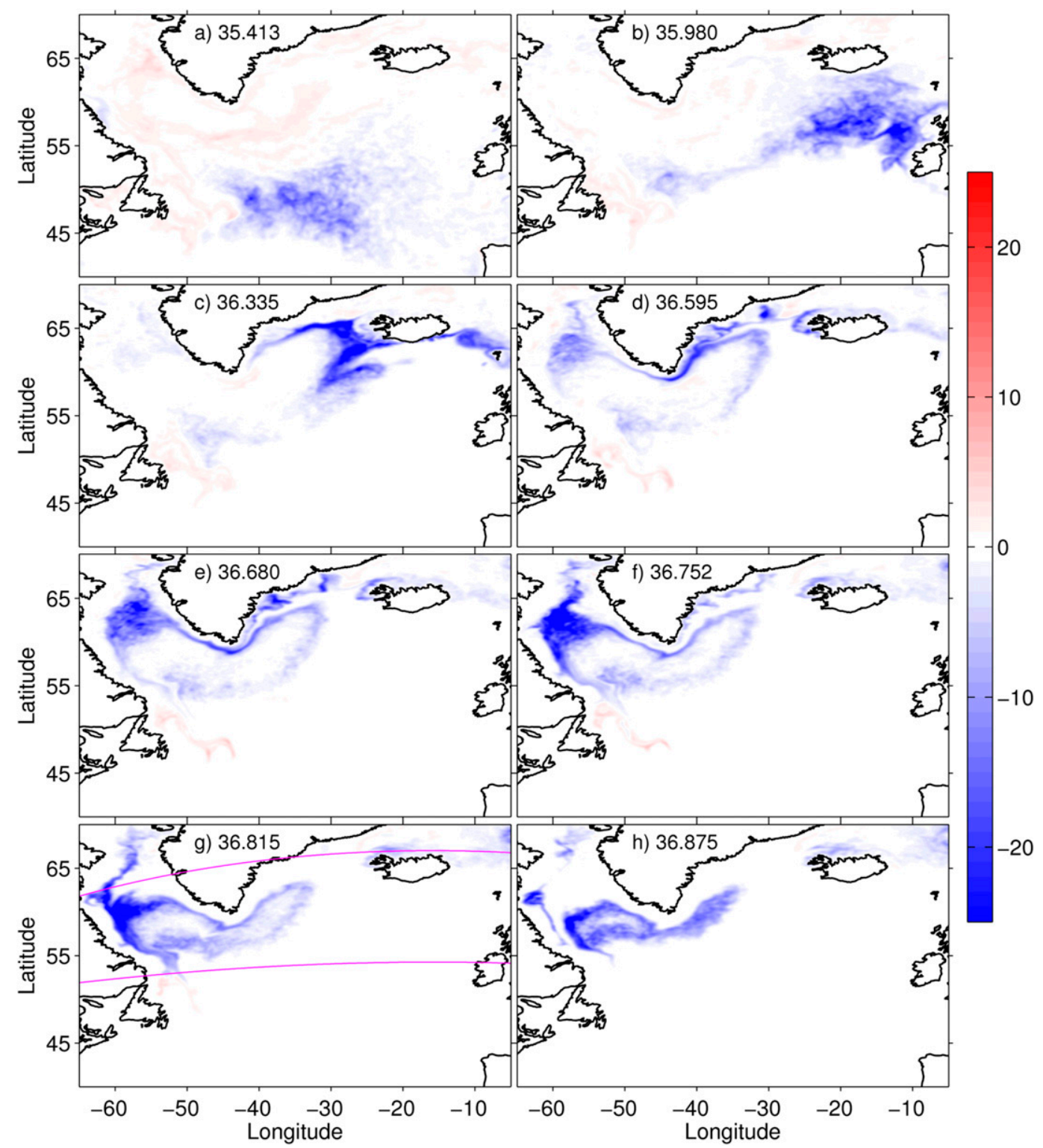

FIG. 13. As in Fig .12, but for the surface-buoyancy-forced diapycnal transformation per unit area $\left(10^{-6} \mathrm{~m} \mathrm{~s}^{-1}\right)$, calculated from the local density flux $D$ in Eq. (3) and surface density. Note that the progression of SPMW convection sites around the subpolar gyre with increasing density is similar to Brambilla et al. (2008).

restratification. These eddies and filaments can be seen in a snapshot of the modeled temperature in winter (Fig. 17a), and the results are quite similar to those presented in idealized models (e.g., Jones and Marshall 1997; Rousset et al. 2009). In addition, the western Greenland Current becomes unstable near $60^{\circ} \mathrm{N}$ (Eden and Böning 2002; Brandt et al. 2007). It meanders to the west and often sheds eddies of warm saline Irminger water into the Labrador Sea interior, providing the buoyancy supply for restratification (Hátún et al. 2007). The boundary current instability and associated eddy shedding create an area of high eddy kinetic energy (EKE) near $62^{\circ} \mathrm{N}$ that can be seen in both the model results and observations (Fig. 17b). The exact location of the modeled high EKE region is slightly to the north and east, compared to the altimetric observations of Lilly et al. (2003). This shift can impact the stratification, deep convection, and water mass transformation in the northwestern Labrador Sea.

The eddy stirring in model, as evidenced in the snapshot in Fig. 17a, increases the horizontal density gradient and mixing. Where the eddy stirring becomes 


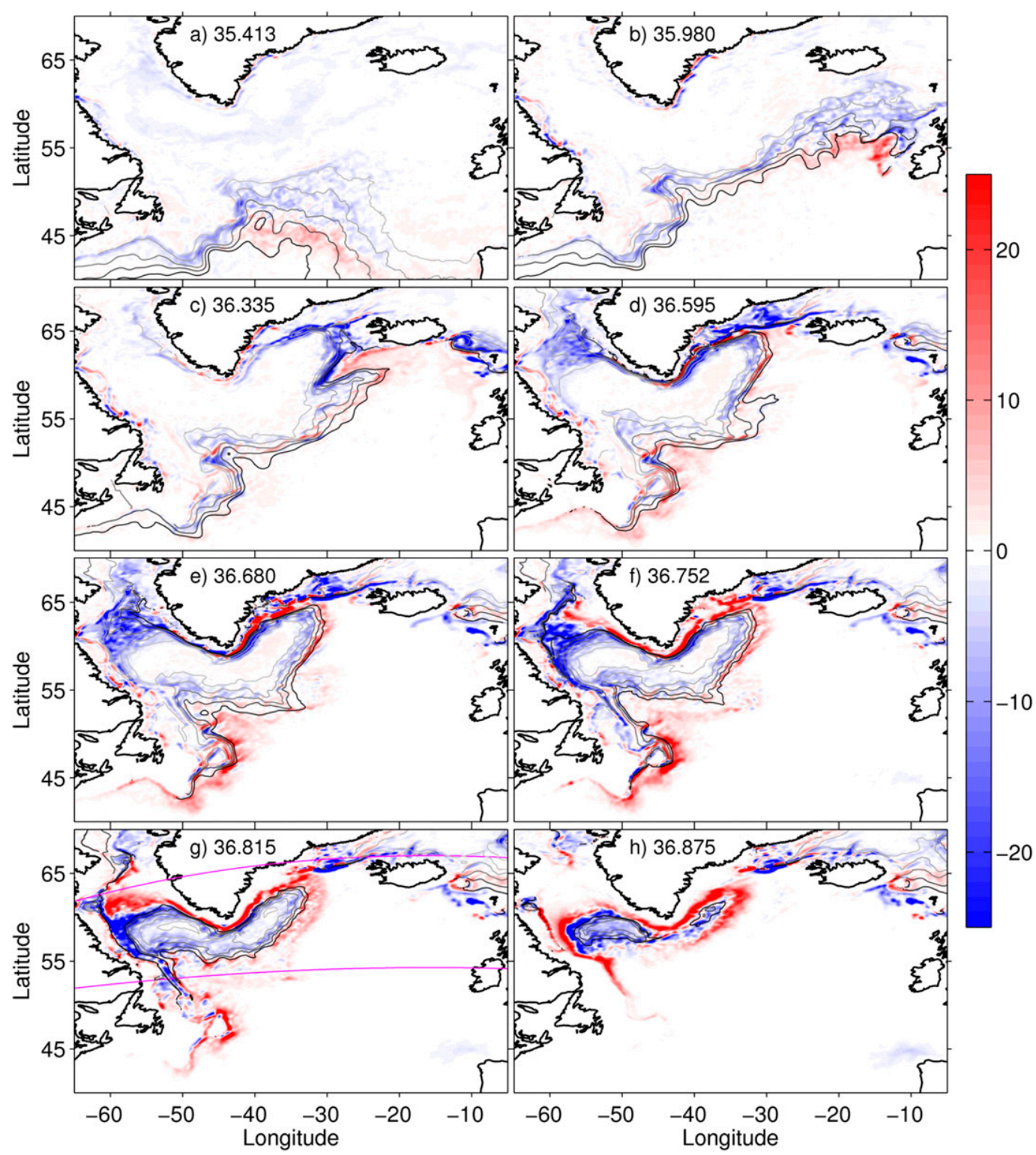

FIG. 14. As in Fig. 12, but for the interior-mixing-induced diapycnal transformation per unit area $\left(10^{-6} \mathrm{~m} \mathrm{~s}^{-1}\right)$; overlaid in contours are the depth of isopycnic surfaces $(50,100,200,300,400 \mathrm{~m}$, respectively). Restratification of deep winter mixed layers by mesoscale eddy mixing creates the red upwelling (warming) regions surrounding convection sites.

important can be shown in the eddy density flux. The average magnitude of eddy density flux $\left(u^{\prime 2}+v^{\prime 2}\right)^{1 / 2} \rho^{\prime}$ (Fig. 17c) shows that eddy stirring is strong to the north of the deep convection site, where the warm water is supplied from the west Greenland Current, and to the south where the warm water is supplied from recirculation offshore of the deep Labrador Current (possibly warmed by interaction with the North Atlantic Current). The distribution of the average magnitude of the diffusive density flux $A_{H} \nabla \rho$ (Fig. 17d) is similar to the wintertime MLD pattern, with elevated density flux surrounding the newly convected LSW, and the transformation as shown in Fig. 14h. These results suggest that the transformation is due to horizontal mixing within the wintertime deep MLD, which is enhanced by eddy stirring. Note that the processes of eddy stirring and mixing take place simultaneously: the eddy stirring sharpens the scalar gradients and enhances the mixing, which in turn rapidly decreases the gradients (Müller and Garrett 2002). 


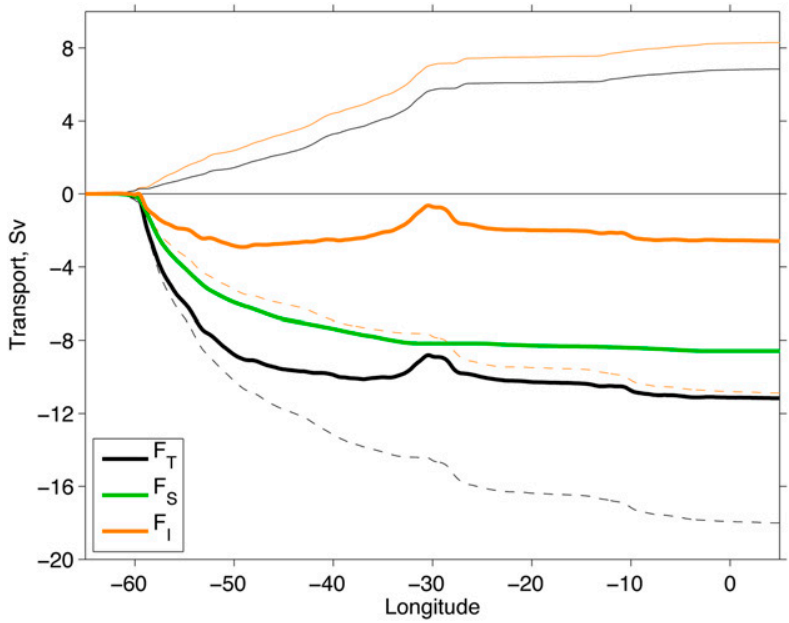

FIG. 15. Eastward accumulation of the modeled total $F_{T}$ (black), surface-forced $F_{S}$ (green), and interior-mixing-induced $F_{I}$ (orange) transformations across $\sigma_{2}=36.815 \mathrm{~kg} \mathrm{~m}^{-3}$ from about $52^{\circ}$ to $65^{\circ} \mathrm{N}$ in the subpolar North Atlantic (between the two magenta lines in Figs. $12 \mathrm{~g}, 13 \mathrm{~g}$, and $14 \mathrm{~g}$ ). Thin lines denote accumulations of transformation toward lighter water (solid) and denser water (dashed) separately. Surface-forced transformation is toward denser water only and appears dominant in the total transformation across this density surface, whereas the mixing-induced transformations are toward both lighter and denser waters (of similar magnitude).

In the rest of this section, we focus on the water mass transformation in two regions of the subpolar North Atlantic: 1) the northwestern Labrador Sea between the WOCE/CLIVAR line AR7W and the Davis Strait and 2) the western Newfoundland Basin.

\section{1) The NORTHWEStern LABRAdor SEA}

The water properties and circulation in the Labrador Sea are often observed along the AR7W line (e.g., Pickart et al. 2002; Yashayaev 2007; Pickart and Spall 2007; Hall et al. 2013). The modeled mean velocity across this section is shown in Fig. 18a. The modeled strong boundary currents over the continental slopes, stronger on the Greenland side, and the barotropic (or depth independent) interior recirculation patterns agree well with the observations based on six lowered acoustic Doppler current profiler (LADCP) surveys during 1995-2008 (Hall et al. 2013, their Fig. 5). The barotropic nature of the velocity components in the Labrador Sea has also been documented in Lilly et al. (1999) and Lilly and Rhines (2002) and in Cuny et al. (2005) using moored currentmeter data. The modeled time mean overturning streamfunctions $\psi_{z}$ and $\psi_{\sigma}$ across the AR7W line are displayed in Figs. $15 \mathrm{~b}$ and $15 \mathrm{c}$, respectively. The modeled maximum overturning in $\psi_{z}$ is $1.2 \mathrm{~Sv}$ near $840 \mathrm{~m}$, similar to $1 \mathrm{~Sv}$ near $800 \mathrm{~m}$ in Pickart and Spall (2007) based on hydrographic data from 1990-97. The modeled maximum overturning in $\psi_{\sigma}$ is $10 \mathrm{~Sv}$ across $36.75 \mathrm{~kg} \mathrm{~m}^{-3}\left(\sigma_{\theta}=27.68 \mathrm{~kg} \mathrm{~m}^{-3}\right)$, much higher than the 2-Sv density-space overturning across $27.70 \mathrm{~kg} \mathrm{~m}^{-3}$ in Pickart and Spall (2007). The difference in $z$-space and $\sigma$-space overturning in our model arises from the Irminger water in the boundary current being cooled/freshened within the Labrador Sea yet entering and exiting the region at nearly the same depth (Fig. 18a).

The time mean streamfunction $\psi_{\sigma}$ across the AR7W line (Fig. 18c) essentially describes the net horizontal transports $F_{N}$ and the total diapycnal transformation $F_{T}$ for the northwestern Labrador Sea between the AR7W line and the Davis Strait (Fig. 19), as the modeled diapycnal overturning across the Davis Strait is small $(\sim 0.3 \mathrm{~Sv})$ and the volume change within the Labrador Sea over 5 years is negligible. The results show that, on annual mean, about $10-\mathrm{Sv}$ SPMW is transformed into LSW in northwestern Labrador Sea and both surface forcing and interior mixing are important. The surface forcing $F_{S}$ is responsible for about 6-Sv LSW, mostly in dense classical LSW (cLSW), whereas the mixing $F_{I}$ converts about 4-Sv dense cLSW (which is surface forced) and 5-Sv SPMW into LSW.

It should be noted that the hydrographic data along AR7W line are collected mostly in spring. Thus, it is unclear if or to what extent the results of Pickart and Spall (2007) represent the annual mean. To examine this, the seasonal variability of the modeled net volume transports $F_{N}$ and the water mass transformations $F_{T}$, $F_{S}$, and $F_{I}$ is displayed in Fig. 20, corresponding to the annual mean profiles of Fig. 19. The net transport $F_{N}$ does vary on a seasonal time scale, with stronger (weaker) transports across a higher (lower) density in April (December). The average of $F_{N}$ over May-July actually is similar to the annual mean, which implies that the diapycnal streamfunction $\psi_{\sigma}$ of Pickart and Spall (2007) is indeed representative of the annual mean $F_{N}$ and $F_{T}$. Similar to that shown in Fig. $5, F_{T}$ and $F_{N}$ differ significantly on seasonal time scales because of the large volume change associated with the accumulation and drainage of dense water (Figs. 20a,b). The total $F_{T}$, surface-forced $F_{S}$, and interior-mixing-induced $F_{I}$ transformations exhibit a similar pattern of seasonal variation (Figs. 20b-d). This result suggests that the $F_{S}$ and $F_{I}$ are not necessary independent from each other in the Labrador Sea: surface buoyancy loss enhances the vertical mixing and the newly convected dense water at the base of the MLD provides source for the mixinginduced transformation.

The above discussion suggests that the 2-Sv diapycnal overturning in Pickart and Spall (2007) should be representative of the annual mean water mass transformation in the northwestern Labrador Sea. However, it is worth pointing out that the 2-Sv overturning of 

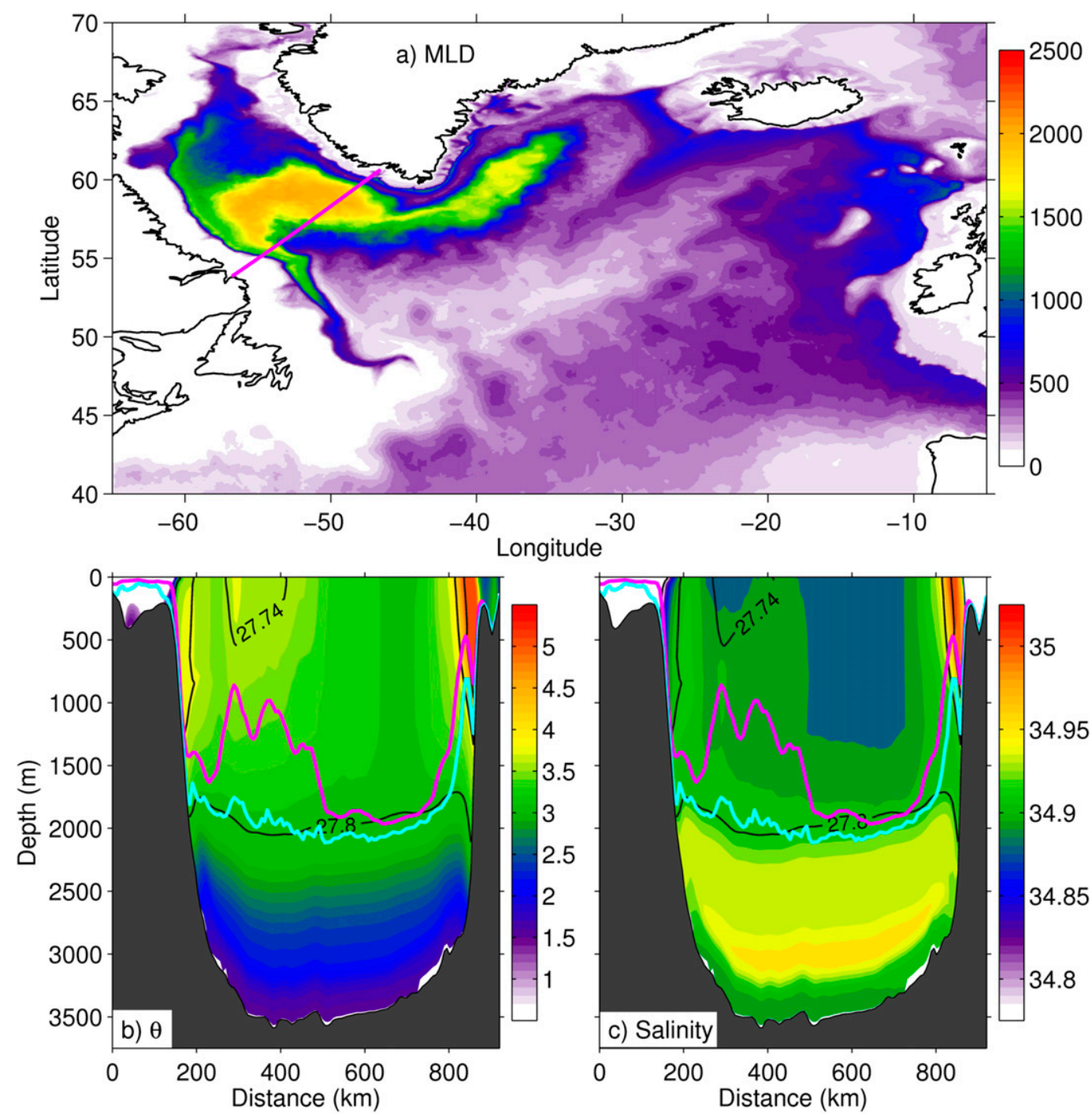

FIG. 16. (a) Modeled average wintertime (March) MLD (m) in the subpolar North Atlantic; the magenta line marks the location of WOCE AR7W line across the Labrador Sea. The corresponding modeled mean (b) potential temperature $\theta\left({ }^{\circ} \mathrm{C}\right)$ and (c) salinity along the AR7W line in March; thick magenta (cyan) lines denote the average (maximum) MLD in March; the black contours are isopycnic surfaces.

Pickart and Spall (2007) is somewhat at odds with the total LSW production rate based on the observed CFC tracer inventory [11.7 Sv in LeBel et al. (2008)]. Note that the production rate based on tracer inventory, termed ventilation rate in Brandt et al. (2007), can be higher than the formation rate. But the difference is primarily in the upper LSW, which contributes a small part of total LSW [3.5 out of $11.7 \mathrm{~Sv}$ in LeBel et al. (2008)]. The repeat LADCP surveys along the AR7W by Hall et al. (2013) show that the volume transport of the eastern boundary current above $\sigma_{\theta}$ of 27.74 is $4-5 \mathrm{~Sv}$ higher than that of the western boundary current, indicating that the diapycnal transformation in the northwestern Labrador Sea can be higher than $2 \mathrm{~Sv}$. Perhaps some of this disagreement also comes from the neglect of eddy transports between boundary current and interior in the Pickart and Spall (2007) estimate, which argues that much of the water mass transformation occurs within the narrow boundary current. Nevertheless, we believe our model Labrador Sea transformation is too large.

\section{2) The Western Newfoundland BASIN}

Similar to Figs. 19 and 20 for the northwestern Labrador Sea, Figs. 21 and 22 display the mean and the seasonal variability of the net transports $F_{N}$ and the water mass transformations $\left(F_{T}, F_{S}\right.$, and $\left.F_{I}\right)$ in the western Newfoundland Basin, defined as the longitude/latitude range of $55^{\circ}-35^{\circ} \mathrm{W}, 40^{\circ}-53^{\circ} \mathrm{N}$ (Fig. 1). The western 

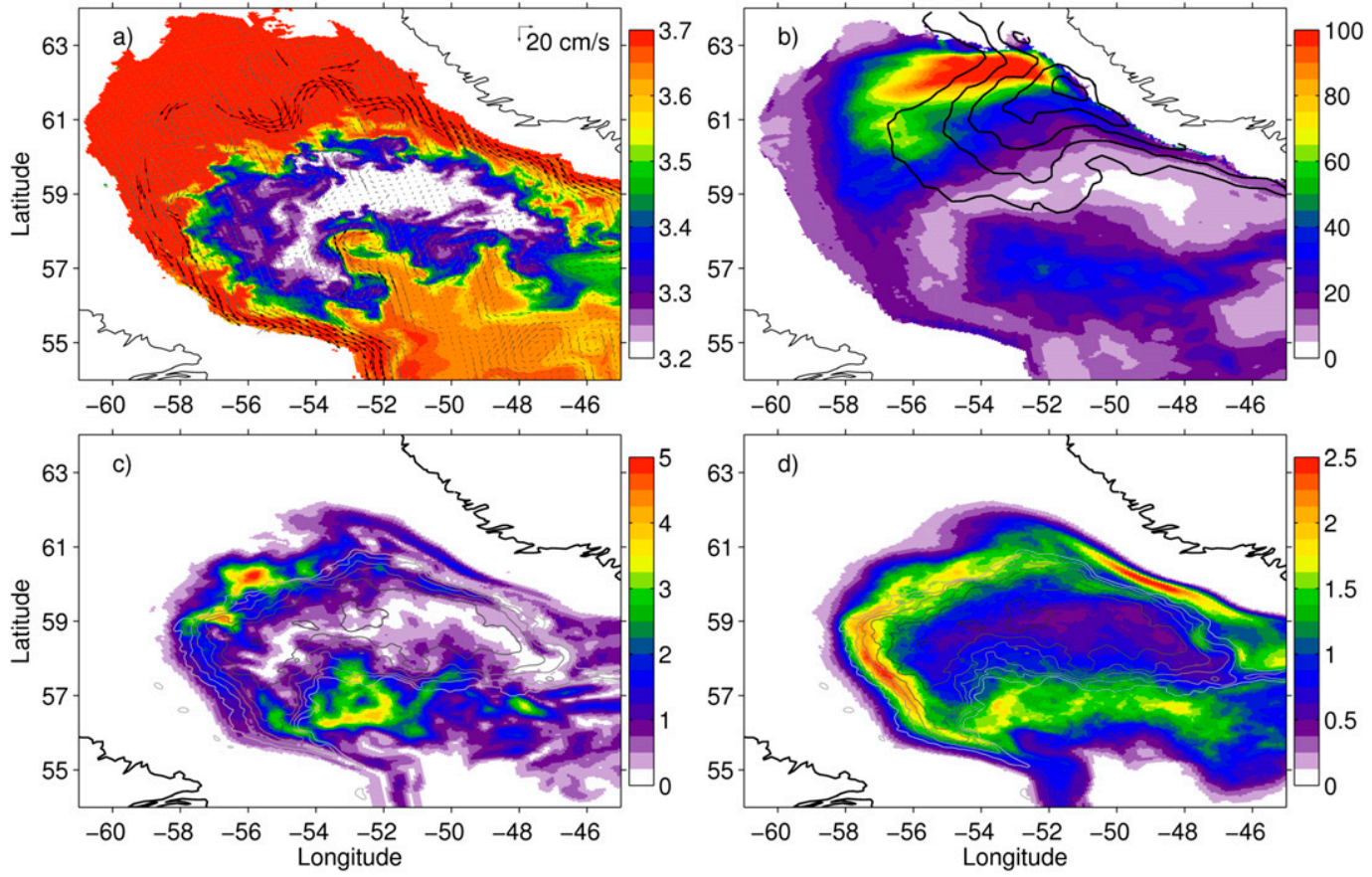

FIG. 17. (a) A snapshot of modeled potential temperature $\theta$ and current vectors on 1 Mar (year 20) for model layer 47 connected with diapycnal transformation seen in Fig. 14h. Eddies and filaments of warm water intrude the newly convected Labrador Sea Water in the interior. (b) Modeled EKE $\left(\mathrm{cm}^{2} \mathrm{~s}^{-2}\right)$ in the Labrador Sea for layer 47 based on results for years 16-20. The overlaid black contours are observed surface EKE speed (2EKE) ${ }^{1 / 2}$ of 20, 23, 26, 29, and $32 \mathrm{~cm} \mathrm{~s}^{-1}$ from Lilly et al. (2003, their Fig. 24); note the slight shift in maximum EKE in the model results. (c) Average magnitude of the modeled eddy density $\left(u^{2}+v^{2}\right)^{1 / 2} \rho^{\prime}\left(10^{-4} \mathrm{~kg} \mathrm{~m}^{-3} \mathrm{~m} \mathrm{~s}^{-1}\right)$, and (d) the average magnitude of the horizontal diffusive density flux $A_{H} \nabla \rho\left(10^{-4} \mathrm{~kg} \mathrm{~m}^{-3} \mathrm{~m} \mathrm{~s}^{-1}\right)$ in the Labrador Sea. The gray to black contours are wintertime mixed layer depth from 1500 to $2000 \mathrm{~m}$, illustrating the area of significant eddy stirring and horizontal diffusion surrounding the thick layer of LSW.

Newfoundland Basin is a transition region between the subpolar and subtropical gyres as well as between the upper and lower limb of the AMOC. Significant transformation takes place in this relatively small region: in the surface mixed layer, approximately 8 -Sv light water $\left(<35.15 \mathrm{~kg} \mathrm{~m}^{-3}\right)$ is transformed into denser water of $35.15-36.3 \mathrm{~kg} \mathrm{~m}^{-3}$. This transformation is mostly surface forced (see Figs. 6h, 7h, and 8h and 12a, 13a, and 14a). Below the mixed layer, about 5-Sv LSW is transformed toward the lighter SPMW density range via interior mixing (Fig. 21). This transformation, opposite to that which takes place in the northwestern Labrador Sea (Fig. 19), closes the modeled local diapycnal overturning cell in subpolar region as seen in Figs. 2a and 3a. On the seasonal time scale, the variation of the overturning density of the $F_{N}$ in the western Newfoundland Basin (Fig. 22a) matches that of $F_{N}$ in the northwestern Labrador Sea (Fig. 17a). As a result, the densities of the modeled maximum overturning streamfunction vary seasonally in the subpolar North Atlantic but are nearly constant south of this transition region. The seasonal variation of the diapycnal transformations in Figs. $22 \mathrm{~b}-\mathrm{d}$ further show that transformation toward lighter water is interior-mixinginduced $F_{I}$ and the transformation toward lighter water is primarily surface-forced $F_{S}$.

Detailed circulation pattern and model layer structure are examined in Fig. 23 to illustrate how the diapycnal transformation toward lighter water takes place in the Newfoundland Basin. Figures 23a and 23b show zoomed transformation distribution across the density surface 36.752 , along with the transport vectors per unit width for the warm water above and for the LSW below. The fullwater column meridional velocity and the diapycnal transformation along $47^{\circ} \mathrm{N}$ are shown in Figs. $23 \mathrm{c}$ and $23 \mathrm{~d}$. The results show that the transformation takes place between the southward-flowing deep western boundary current (DWBC) and the northward-flowing North Atlantic Current (NAC). This diapycnal transformation occurs in the model domain where the vertical coordinate is fixed (i.e., level and nonisopycnic) and that is below the wintertime mixed layer depth. Thus, one can expect numerically induced diapycnal mixing (when in nonisopycnic space), and it will be a function of the model vertical configuration and horizontal mixing 

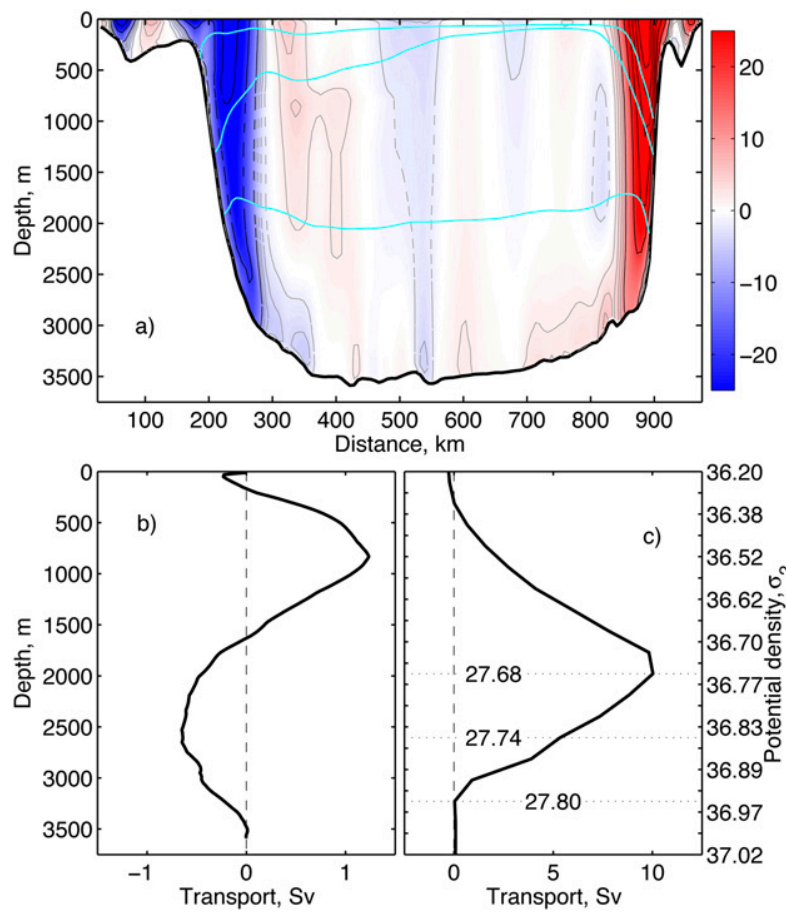

FIG. 18. (a) Modeled mean normal velocity $\left(\mathrm{cm} \mathrm{s}^{-1}\right)$ across the WOCE AR7W line in the Labrador Sea; positive values indicate northwest flows; three cyan lines denote $\sigma_{\theta}$ surfaces of 27.68, 27.74, and $27.80 \mathrm{~kg} \mathrm{~m}^{-3}$, respectively. Modeled mean overturning streamfunction across the AR7W line with respect to (b) depth and (c) density $\sigma_{2}$ (dotted lines denote the corresponding key isopycnals in $\sigma_{\theta}$ ). The large difference between (b) and (c) comes from the cooling, freshening, and densification of the upper Irminger water from the eastern boundary current to the western boundary current at the same $z$ level.

parameterization (Griffies et al. 2000). Observations do show intensified vertical mixing in the western boundary current near $47^{\circ} \mathrm{N}$ (Walter et al. 2005), and the modeled circulation pattern along $47^{\circ} \mathrm{N}$ as shown in Fig. $23 \mathrm{c}$ is very similar to observations (Mertens et al. 2014). Since we cannot easily differentiate between physical and numerically induced mixing in this area, one cannot be certain if significant diapycnal mixing actually occurs between the DWBC and the NAC in the real ocean. It is known, however, that isopycnal mixing between the DWBC and the NAC occurs in this region, which explains the different oxygen content between the NAC and its upstream source water in the Gulf Stream (Clarke et al. 1980). The LSW south of the Newfoundland Basin is also warmer and saltier than its upstream source in the Labrador Sea (LeBras et al. 2017).

\section{Summary and discussion}

The Atlantic meridional overturning circulation (AMOC) is a fundamental element in Earth's climate,

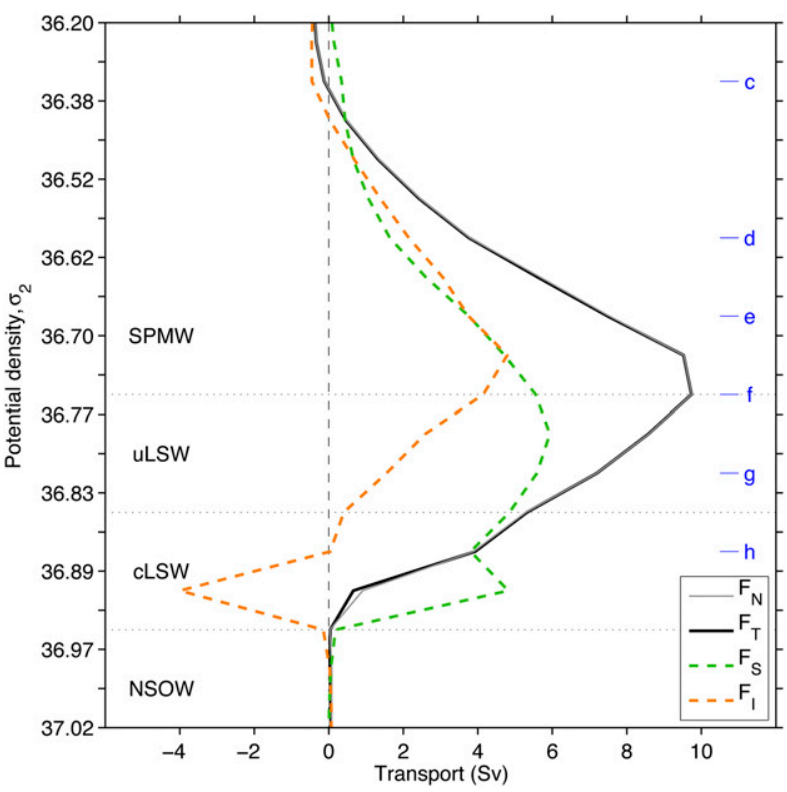

FIG. 19. Modeled 5-yr mean net transport $F_{N}$ and the total $F_{T}$, surface-forced $F_{S}$, and mixing-induced $F_{I}$ diapycnal water mass transformations in the northwestern Labrador Sea between the WOCE AR7W line and the Davis Strait. The water masses shown are SPMW, upper and classical Labrador Sea Water (uLSW; $\mathrm{cLSW}$ ), and NSOW. Blue labels $\mathrm{c}-\mathrm{h}$ are density surfaces corresponding to panels (c)-(h) in Figs. 12-14.

being responsible for a large amount of heat and freshwater transports. The essence of AMOC and the associated heat/freshwater transports lies in the diapycnal transformation of the warm saline water in the upper limb into the cold fresh North Atlantic Deep Water (NADW) in the lower limb in the North Atlantic (as well as the transformation toward lighter water in other basins to close the cycle). Many studies have examined the transformation in the North Atlantic that is forced by the surface buoyancy fluxes, using the thermodynamic framework of Walin (1982) and Speer and Tziperman (1992). Interior mixing can also induce diapycnal water mass transformation, yet basic questions, such as to what extent the water mass transformation is surface forced, where and how the mixing-induced transformation becomes important, remain largely unanswered.

This study maps the three-dimensional structure of the total and surface-forced transformations in the upper North Atlantic Ocean (with their difference interpreted as transformation due to interior mixing). Using high-resolution numerical results that have been shown to represent quite well the large-scale AMOC and subtropical/subpolar gyres in the North Atlantic, we show the following:

1) Strong transformation toward denser water takes place seamlessly from the subtropical to subpolar 


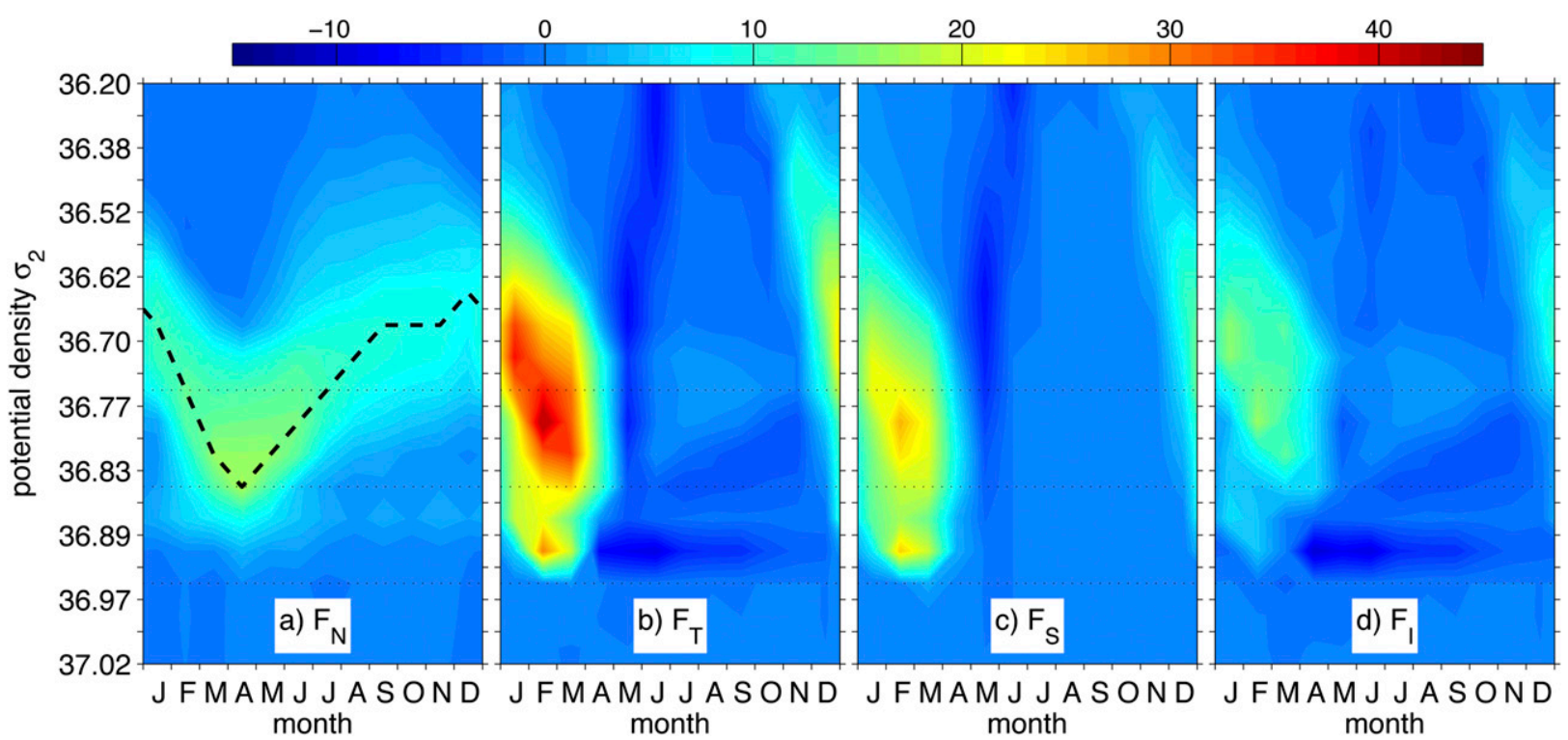

FIG. 20. Seasonal variation of the modeled (a) net transport $F_{N}$ and the modeled (b) total $F_{T}$, (c) surface-forced $F_{S}$, and (d) mixinginduced $F_{I}$ diapycnal water mass transformations in the northwestern Labrador Sea as shown in Fig. 19. The thick dashed black line denotes the seasonal variation of density surface across which the net transport $F_{N}$ into the region is largest.

North Atlantic, first along the western boundary current system of the Florida Current, the Gulf Stream, and the North Atlantic Current and then along the cyclonic subpolar gyre from the polar front

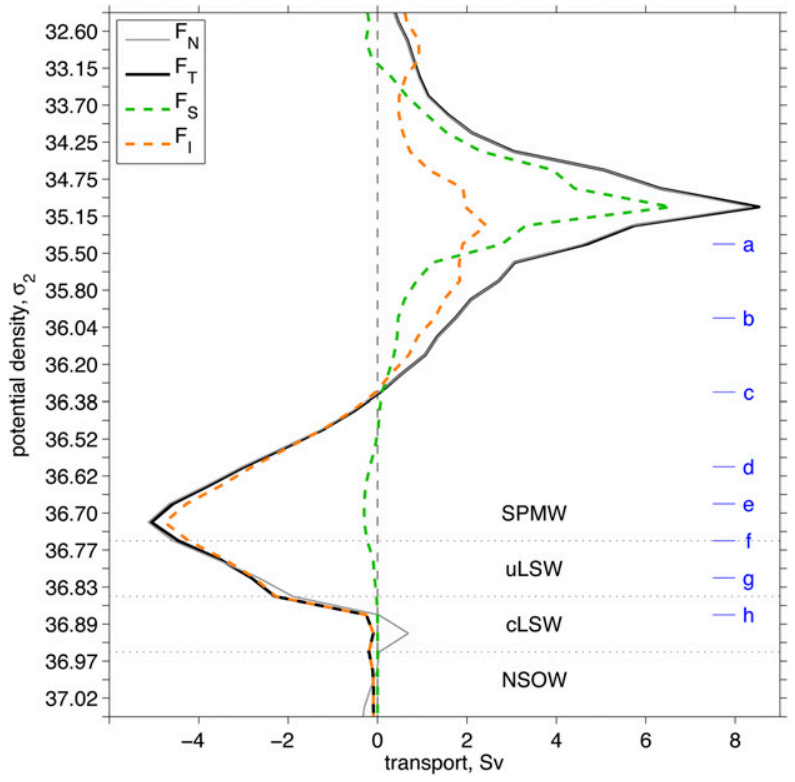

FIG. 21. Modeled 5-yr mean net transport $F_{N}$ and the total $F_{T}$, surface-forced $F_{S}$, and mixing-induced $F_{I}$ diapycnal water mass transformations in the subpolar-subtropical transition region $\left(55^{\circ}-\right.$ $35^{\circ} \mathrm{W}$ and $40^{\circ}-52^{\circ} \mathrm{N}$; see Fig. 1). The upper part shows transformation of the warm water in the North Atlantic Current toward denser water due to (primarily) surface cooling (blue patch in Figs. 7h and 13a); the low part shows the transformation of Labrador Sea Water in the southward deep western boundary current toward lighter water due to interior mixing (red patch in Figs. $14 \mathrm{e}-\mathrm{g}$ ). toward the Iceland basin, around the Reykjanes Ridge and Greenland, and into the Labrador Sea. A large part of the transformation is forced directly by the surface buoyancy loss along the northward pathway of the upper AMOC limb and is captured in the framework of Walin (1982). Surface-forced transformation also occurs in warming of upwelled cold water near West Africa.

2) Mixing plays a significant role in diapycnal transformation in several regions:

(i) In the southern part of subtropical gyre, 4.7-Sv Subtropical Mode Water (SPTW) is transformed into lighter water along a basinwide rim between $15^{\circ}$ and $30^{\circ} \mathrm{N}$ (Fig. 8). This transformation is due to horizontal diffusive mixing in the southwestward Sverdrup flow in the wintertime mixed layer before it is subducted into the isopycnic domain (Figs. 9 and 10).

(ii) In the northwestern Labrador Sea, lateral mixing within the deep mixed layer transforms about 5-Sv SPMW into LSW and about 4 Sv of dense cLSW (that was transformed by surface buoyancy fluxes) into lighter cLSW (Fig. 18). Eddies play an important role in stirring warm water into the convected region and increasing the horizontal mixing.

(iii) In the western Newfoundland Basin, horizontal mixing between DWBC and NAC transforms about 5-Sv LSW toward lighter water. This mixing occurs along nonisopycnic coordinates below the wintertime mixed layer and is the result of numerical mixing when in level space. 


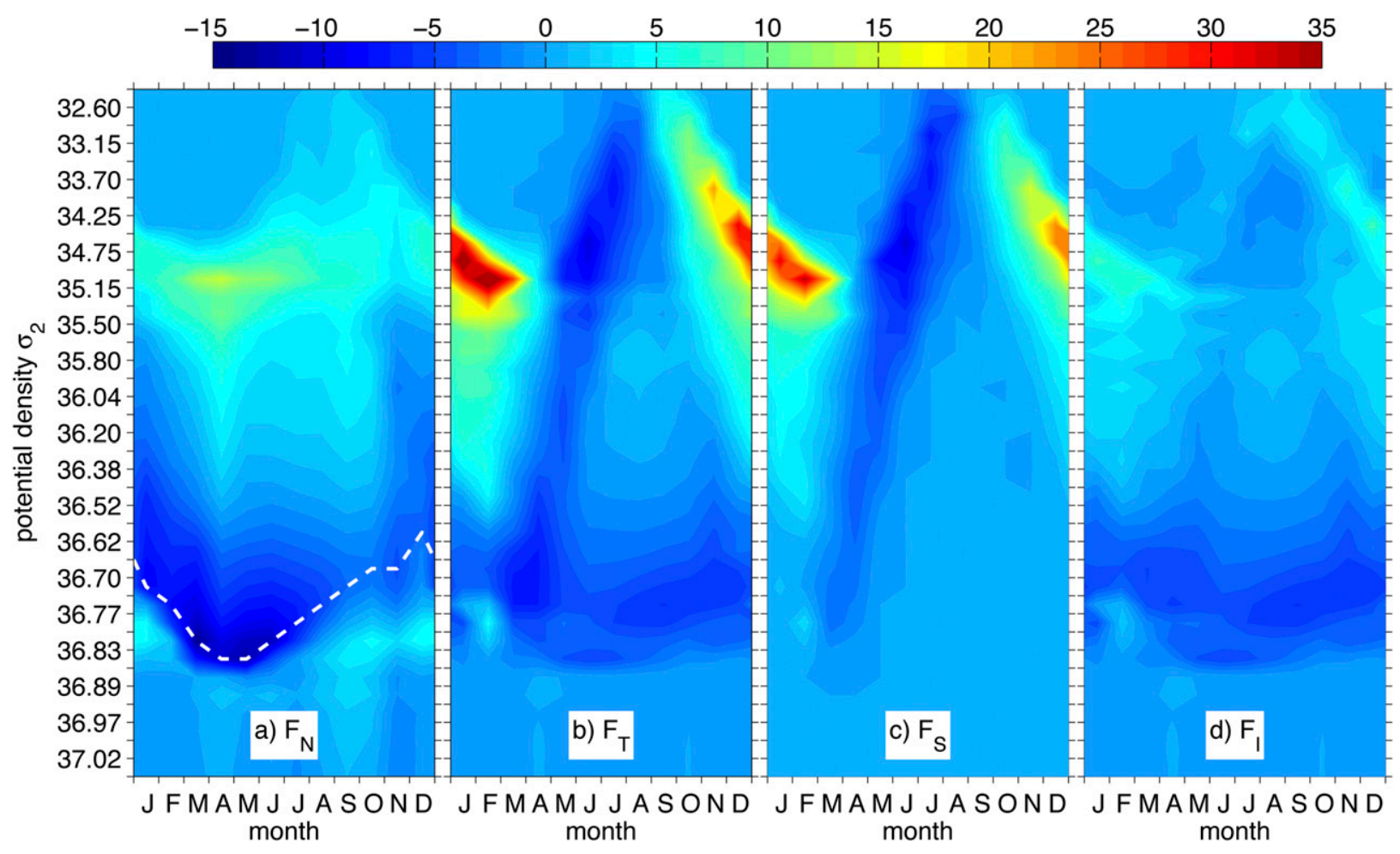

FIG. 22. Seasonal variation of the modeled (a) net transport $F_{N}$ and the modeled (b) total $F_{T}$, (c) surface-forced $F_{S}$, and (d) mixinginduced $F_{I}$ diapycnal water mass transformations in the subpolar-subtropical transition region $\left(55^{\circ}-35^{\circ} \mathrm{W}\right.$ and $\left.40^{\circ}-52^{\circ} \mathrm{N}\right)$. The dashed white line denotes the density seasonal variation of density surface across which the net transport $F_{N}$ out of the region is largest.

3) The patterns of diapycnal transformations toward lighter/denser water are not zonal. Thus, the zonally integrated, two-dimensional representation of the meridional overturning streamfunction with respect to density and latitude underestimates the total diapycnal transformation: In the southern subtropical gyre, the transformation of STMW is about $4.7 \mathrm{~Sv}$, nearly $50 \%$ higher than the zonal integration value of 3.2 Sv (Fig. 11). In the western subpolar North Atlantic, the transformation in the LSW regime is about $16 \mathrm{~Sv}, 60 \%$ higher than the zonally integrated value of $10 \mathrm{~Sv}$ (Fig. 15).

It is important to keep in mind that the results presented in this study are based on one numerical simulation, and several limitations need to be mentioned. First, it is primarily the parameterized horizontal mixing in the mixed layer that drives the diapycnal water mass transformation by mixing, and thus the model results could be dependent upon the choice made for the eddy mixing parameterization. Although some use refined parameterization to better take into account submesoscale processes (i.e., Fox-Kemper et al. 2008), the model used here, like many traditional ocean general circulation models (OGCMs), parameterizes mixing by unresolved processes by using a combination of a Laplacian and biharmonic operators. Second, the representation of baroclinic instability, and thus the restratification process in numerical models, is sensitive to model physics, especially the vertical coordinates (e.g., Rousset et al. 2009). An accurate representation of the water masses in key regions such as the Labrador Sea also involves buoyancy input of low-salinity Arctic waters, which can be a challenge even for high-resolution models (e.g., Treguier et al. 2005). Furthermore, quantification of the numerically induced mixing across steep isopycnals, especially in boundary currents and frontal regions, remains challenging and lacks accuracy (Griffies et al. 2000; Ilicak et al. 2012; Ilicak 2016). These limitations emphasize the need to perform similar analysis with other numerical models and/or with different mixing parameterizations to determine their robustness. Nevertheless, our model results compare well with the observations in terms of large-scale AMOC and gyre circulation (Xu et al. 2015, 2016), and therefore one may surmise that it is a reasonable representation of the water mass transformations that take place in the North Atlantic.

Despite a history of intensive observations in the North Atlantic, it remains a challenge to map the structure of 


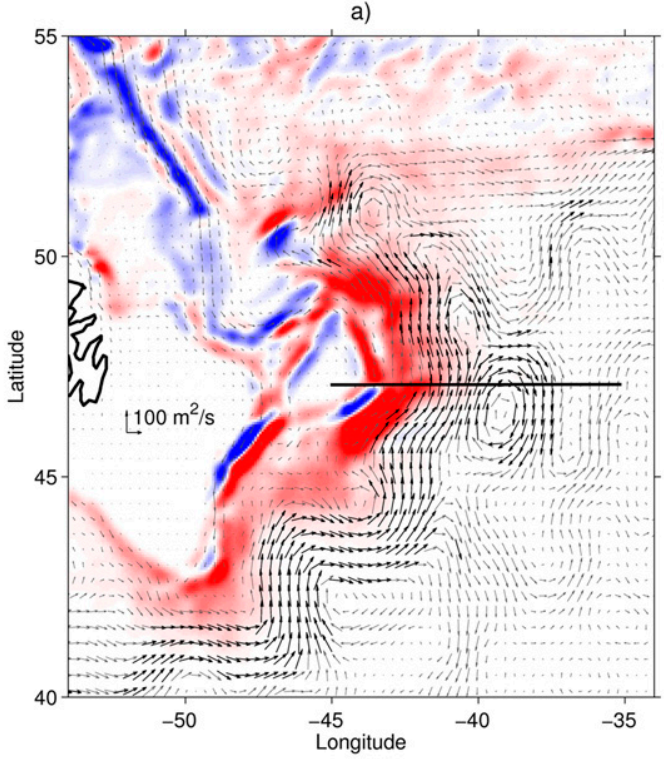

c)

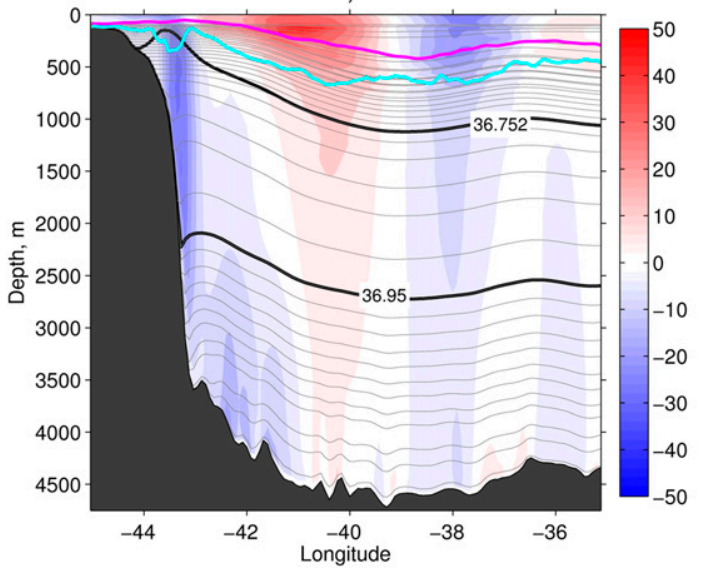

b)

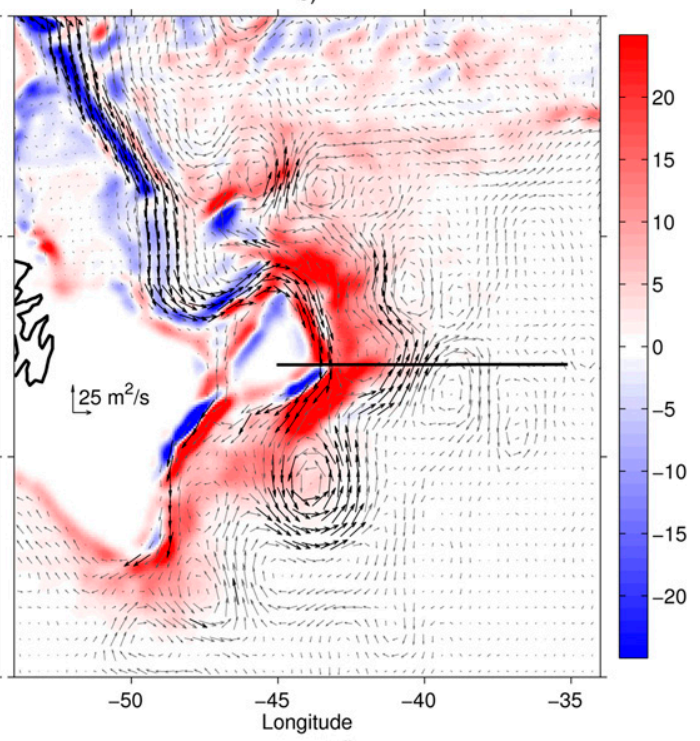

d)

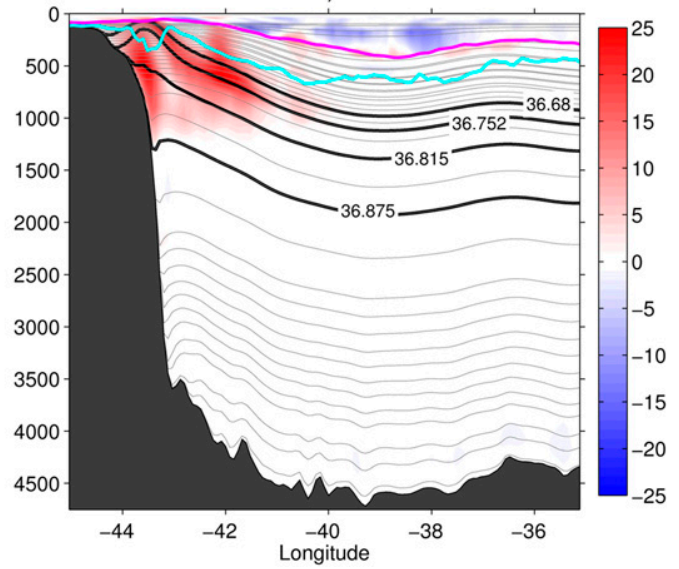

FIG. 23. Modeled time mean mixing-induced diapycnal transformation $\left(10^{-6} \mathrm{~m} \mathrm{~s}^{-1}\right)$ across $\sigma_{2}$ surface of $36.752 \mathrm{~kg} \mathrm{~m}^{-3}$ (Fig. 14f) in the western Newfoundland Basin, overlaid with vectors of transport per unit width for (a) the water with $\sigma_{2}<36.752 \mathrm{~kg} \mathrm{~m}^{-3}$ and (b) the LSW with $36.752 \leq \sigma_{2}<36.95 \mathrm{~kg} \mathrm{~m}^{-3}$; the horizontal line marks a zonal section at $47^{\circ} \mathrm{N}$. Modeled mean (c) meridional velocity $\left(\mathrm{cm} \mathrm{s}^{-1}\right)$ and (d) mixing-induced diapycnal transformation $\left(10^{-6} \mathrm{~m} \mathrm{~s}^{-1}\right)$ along $47^{\circ} \mathrm{N}$. The thick magenta (cyan) line marks the averaged (maximum) wintertime (March) MLD; thick black lines are modeled mean isopycnic surfaces, and thin gray lines are mean locations of model coordinates. Note the diapycnal transformation toward lighter water occurs along the model nonisopycnic coordinate below the wintertime mixed layer.

water mass transformations observationally. The understanding of the diapycnal water mass transformation has been limited mostly to those based on hydrographic sections (e.g., Lumpkin and Speer 2003; Lumpkin et al. 2008) and tracer measurements (e.g., LeBel et al. 2008), which are often temporally too sparse to represent the time-mean transformation and/or do not provide spatial details. In the recent observations such as the Rapid Climate Change (RAPID) program (e.g., Cunningham et al. 2007), the focus is the zonally integrated volume transports without spatial distribution (of both transports and water properties). Further measurements of both volume transports and water properties along key sections, such as the newly implemented Overturning in the Subpolar North Atlantic Program (OSNAP; Lozier et al. 2017) are essential to our understanding of the water mass transformation and to determine if the modeled transformations are realistic.

Acknowledgments. XX and EPC are supported by the NOAA Climate Program Office MAPP Program (Award NA15OAR4310088) and the NSF Physical Oceanography Program (Award 1537136). PBR is supported by the NASA Ocean Surface Topography Science Team Program. 
The numerical simulations were performed on supercomputers at the Navy DoD Supercomputing Resource Center, Stennis Space Center, Mississippi, using computer time provided by the U.S. DoD High Performance Computing Modernization Program.

\section{REFERENCES}

Bacon, S., and P. M. Saunders, 2010: The deep western boundary current at Cape Farewell: Results from a moored current meter array. J. Phys. Oceanogr., 40, 815-829, https://doi.org/ 10.1175/2009JPO4091.1.

— , A. Marshall, N. P. Holliday, Y. Aksenov, and S. R. Dye, 2014: Seasonal variability of the East Greenland Coastal Current. J. Geophys. Res. Oceans, 119, 3967-3987, https://doi.org/ 10.1002/2013JC009279.

Bailey, D. A., P. B. Rhines, and S. Häkkinen, 2005: Formation and pathways of North Atlantic Deep Water in a coupled iceocean model of the Arctic-North Atlantic Oceans. Climate Dyn., 25, 497-516, https://doi.org/10.1007/s00382-005-0050-3.

Bleck, R., 2002: An oceanic general circulation model framed in hybrid isopycnic-Cartesian coordinates. Ocean Modell., 4, 55-88, https://doi.org/10.1016/S1463-5003(01)00012-9.

Brambilla, E., L. D. Talley, and P. E. Robbins, 2008: Subpolar mode water in the northeastern Atlantic: 2. Origin and transformation. J. Geophys. Res., 113, C04026, https://doi.org/ 10.1029/2006JC004063.

Brandt, P., A. Funk, L. Czeschel, C. Eden, and C. Böning, 2007: Ventilation and transformation of Labrador Sea Water and its rapid export in the deep Labrador Current. J. Phys. Oceanogr., 37, 946-961, https://doi.org/10.1175/JPO3044.1.

Burkholder, K., and S. Lozier, 2014: Tracing the pathways of the upper limb of the North Atlantic meridional overturning circulation. Geophys. Res. Lett., 41, 4254-4260, https://doi.org/ 10.1002/2014GL060226.

Chassignet, E. P., and Z. D. Garraffo, 2001: Viscosity parameterization and the Gulf Stream separation. From Stirring to Mixing in a Stratified Ocean: Proc. 'Aha Huliko'a Hawaiian Winter Workshop, Honolulu, HI, University of Hawai'i at Mānoa, 37-41.

- and X. Xu, 2017: Impact of horizontal resolution $\left(1 / 12^{\circ}\right.$ to $\left.1 / 50^{\circ}\right)$ on Gulf Stream separation, penetration, and variability. J. Phys. Oceanogr., 47, 1999-2021, https://doi.org/10.1175/ JPO-D-17-0031.1.

— - L. T. Smith, G. R. Halliwell, and R. Bleck, 2003: North Atlantic simulation with the Hybrid Coordinate Ocean Model (HYCOM): Impact of the vertical coordinate choice, reference density, and thermobaricity. J. Phys. Oceanogr., 33, 2504-2526, https://doi.org/10.1175/1520-0485(2003)033<2504: NASWTH $>2.0 . \mathrm{CO} ; 2$.

— , and Coauthors, 2006: Generalized vertical coordinates for eddyresolving global and coastal ocean forecasts. Oceanography, 19 (1), 118-129, https://doi.org/10.5670/oceanog.2006.95.

Clarke, R., H. Hill, R. Reiniger, and B. Warren, 1980: Current system south and east of the Grand Banks of Newfoundland. J. Phys. Oceanogr., 10, 25-65, https://doi.org/10.1175/15200485(1980)010<0025:CSSAEO $>2.0 . \mathrm{CO} ; 2$.

Cunningham, S. A., and Coauthors, 2007: Temporal variability of the Atlantic meridional overturning circulation at $26.5^{\circ} \mathrm{N}$. Science, 317, 935-938, https://doi.org/10.1126/science.1141304.

Cuny, J., P. B. Rhines, F. Schott, and J. Lazier, 2005: Convection above the Labrador continental slope. J. Phys. Oceanogr., 35, 489-511, https://doi.org/10.1175/JPO2700.1.
Döös, K., and D. J. Webb, 1994: The Deacon cell and the other meridional cells of the Southern Ocean. J. Phys. Oceanogr., 24, 429-442, https://doi.org/10.1175/1520-0485(1994)024<0429: TDCATO $>2.0 . \mathrm{CO} ; 2$.

Eden, C., and C. W. Böning, 2002: Sources of eddy kinetic energy in the Labrador Sea. J. Phys. Oceanogr., 32, 3346-3363, https:// doi.org/10.1175/1520-0485(2002)032<3346:SOEKEI >2.0.CO;2.

Evans, D. G., and Coauthors, 2017: Recent wind-driven variability in Atlantic water mass distribution and meridional overturning circulation. J. Phys. Oceanogr., 47, 633-647, https:// doi.org/10.1175/JPO-D-16-0089.1.

Fischer, J., F. A. Schott, and M. Dengler, 2004: Boundary circulation at the exit of the Labrador Sea. J. Phys. Oceanogr., 34, 1548-1570, https://doi.org/10.1175/1520-0485(2004)034<1548: BCATEO $>2.0 . C O ; 2$.

— M. Misbeck, R. Zantopp, and N. Nunes, 2010: Interannual to decadal variability of outflow from the Labrador Sea. Geophys. Res. Lett., 37, L24610, https://doi.org/10.1029/2010GL045321.

Fox-Kemper, B., R. Ferrari, and R. W. Hallberg, 2008: Parameterization of mixed layer eddies. Part I: Theory and diagnosis. J. Phys. Oceanogr., 38, 1145-1165, https://doi.org/10.1175/ 2007JPO3792.1.

Griffies, S. M., R. C. Pacanowski, and R. W. Hallberg, 2000: Spurious diapycnal mixing associated with advection in a $Z$-coordinate ocean model. Mon. Wea. Rev., 128, 538-564, https://doi.org/ 10.1175/1520-0493(2000)128<0538:SDMAWA > 2.0.CO;2.

Grist, J. P., S. A. Josey, R. Marsh, Y. O. Kwon, R. J. Bingham, and A. T. Blaker, 2014: The surface-forced overturning of the North Atlantic: Estimates from modern era atmospheric reanalysis datasets. J. Climate, 27, 3596-3618, https://doi.org/ 10.1175/JCLI-D-13-00070.1.

Häkkinen, S., P. B. Rhines, and D. L. Worthen, 2011: Warm and saline events embedded in the meridional circulation of the northern North Atlantic. J. Geophys. Res., 116, C03006, https://doi.org/10.1029/2010JC006275.

Hall, M. M., D. J. Torres, and I. Yashayaev, 2013: Absolute velocity along the AR7W section in the Labrador Sea. Deep-Sea Res. I, 72, 72-87, https://doi.org/10.1016/j.dsr.2012.11.005.

Halliwell, G. R., 2004: Evaluation of vertical coordinate and vertical mixing algorithms in the Hybrid Coordinate Ocean Model (HYCOM). Ocean Modell., 7, 285-322, https://doi.org/ 10.1016/j.ocemod.2003.10.002.

Hansen, B., and S. Østerhus, 2000: North Atlantic-Nordic seas exchanges. Prog. Oceanogr., 45, 109-208, https://doi.org/ 10.1016/S0079-6611(99)00052-X

Hátún, H., C. C. Eriksen, and P. B. Rhines, 2007: Buoyant eddies entering the Labrador Sea observed with gliders and altimetry. J. Phys. Oceanogr., 37, 2838-2854, https://doi.org/10.1175/ 2007JPO3567.1.

Ilicak, M., 2016: Quantifying spatial distribution of spurious mixing in ocean models. Ocean Modell., 108, 30-38, https://doi.org/ 10.1016/j.ocemod.2016.11.002.

—, A. J. Adcroft, S. M. Griffies, and R. W. Hallberg, 2012: Spurious dianeutral mixing and the role of momentum closure. Ocean Modell., 45-46, 37-58, https://doi.org/10.1016/ j.ocemod.2011.10.003.

Iudicone, D., G. Madec, and T. J. McDougall, 2008: Water-mass transformations in a neutral density framework and the key role of light penetration. J. Phys. Oceanogr., 38, 1357-1376, https://doi.org/10.1175/2007JPO3464.1.

Jones, H., and J. Marshall, 1997: Restratification after deep convection. J. Phys. Oceanogr., 27, 2276-2287, https://doi.org/ 10.1175/1520-0485(1997)027<2276:RADC>2.0.CO;2. 
Kara, A. B., H. E. Hurlburt, and A. J. Wallcraft, 2005: Stabilitydependent exchange coefficients for air-sea fluxes. J. Atmos. Oceanic Technol., 22, 1080-1094, https://doi.org/10.1175/ JTECH1747.1.

Khatiwala, S., P. Schlosser, and M. Visbeck, 2002: Rates and mechanisms of water mass transformation in the Labrador Sea as inferred from tracer observations. J. Phys. Oceanogr., 32, 666-686, https://doi.org/10.1175/1520-0485(2002)032<0666: RAMOWM $>2.0 . \mathrm{CO} ; 2$.

Langehaug, H. R., P. B. Rhines, T. Eldevik, J. Mignot, and K. Lohmann, 2012: Water mass transformation and the North Atlantic Current in three multicentury climate model simulations. J. Geophys. Res., 117, C11001, https://doi.org/10.1029/ 2012JC008021.

Large, W. G., J. C. McWilliams, and S. C. Doney, 1994: Oceanic vertical mixing: A review and a model with a nonlocal boundary layer parameterization. Rev. Geophys., 32, 363-403, https://doi.org/10.1029/94RG01872.

LeBel, D. A., and Coauthors, 2008: The formation rate of North Atlantic Deep Water and eighteen degree water calculated from CFC-11 inventories observed during WOCE. Deep-Sea Res. I, 55, 891-910, https://doi.org/10.1016/j.dsr.2008.03.009.

Le Bras, I. A., I. Yashayaev, and J. M. Toole, 2017: Tracking Labrador Sea water property signals along the deep western boundary current. J. Geophys. Res. Oceans, 122, 5348-5366, https://doi.org/10.1002/2017JC012921.

Lilly, J. M., and P. B. Rhines, 2002: Coherent eddies in the Labrador Sea observed from a mooring. J. Phys. Oceanogr., 32, 585-598, https://doi.org/10.1175/1520-0485(2002)032<0585: CEITLS $>2.0 . \mathrm{CO} ; 2$.

— - — M. Visbeck, R. Davis, J. R. Lazier, F. Schott, and D. Farmer, 1999: Observing deep convection in the Labrador Sea during winter 1994/95. J. Phys. Oceanogr., 29, 2065-2098, https:// doi.org/10.1175/1520-0485(1999)029<2065:ODCITL>2.0.CO;2.

_, - _ F. Schott, K. Lavender, J. Lazier, U. Send, and E. D'Asaro, 2003: Observations of the Labrador Sea eddy field. Prog. Oceanogr., 59, 75-176, https://doi.org/10.1016/ j.pocean.2003.08.013.

Lozier, S. M., and Coauthors, 2017: Overturning in the Subpolar North Atlantic Program: A new international ocean observing system. Bull. Amer. Meteor. Soc., 98, 737-752, https://doi.org/ 10.1175/BAMS-D-16-0057.1.

Lumpkin, R., and K. G. Speer, 2003: Large-scale vertical and horizontal circulation in the North Atlantic Ocean. J. Phys. Oceanogr., 33, 1902-1920, https://doi.org/10.1175/ 1520-0485(2003)033<1902:LVAHCI>2.0.CO;2.

,-- , and K. P. Koltermann, 2008: Transport across $48^{\circ} \mathrm{N}$ in the Atlantic Ocean. J. Phys. Oceanogr., 38, 733-752, https:// doi.org/10.1175/2007JPO3636.1.

MacKinnon, J., and Coauthors, 2017: Climate process team on internal wave-driven ocean mixing. Bull. Amer. Meteor. Soc., 98, 2429-2454, https://doi.org/10.1175/BAMS-D-16-0030.1.

Marsh, R., 2000: Recent variability of the North Atlantic thermohaline circulation inferred from surface heat and freshwater fluxes. J. Climate, 13, 3239-3260, https://doi.org/ 10.1175/1520-0442(2000)013<3239:RVOTNA > 2.0.CO;2.

—, S. A. Josey, A. J. G. Nurser, B. A. de Cuevas, and A. C. Coward, 2005: Water mass transformation in the North Atlantic over 1985-2002 simulated in an eddy-permitting model. Ocean Sci., 1, 127-144, https://doi.org/10.5194/os-1-127-2005.

Marshall, J., and Coauthors, 1998: The Labrador Sea deep convection experiment. Bull. Amer. Meteor. Soc., 79, 2033-2058, https:// doi.org/10.1175/1520-0477(1998)079<2033:TLSDCE>2.0.CO;2.
_ D. Jamous, and J. Nilsson, 1999: Reconciling thermodynamic and dynamic methods of computation of water-mass transformation rates. Deep-Sea Res. I, 46, 545-572, https://doi.org/ 10.1016/S0967-0637(98)00082-X.

McCarthy, G. D., and Coauthors, 2015: Measuring the Atlantic meridional overturning circulation at $268^{\circ}$ N. Prog. Oceanogr., 130, 91-111, https://doi.org/10.1016/j.pocean.2014.10.006.

McCartney, M. S., and L. D. Talley, 1982: The subpolar mode water of the North Atlantic Ocean. J. Phys. Oceanogr., 12, 1169-1188, https://doi.org/10.1175/1520-0485(1982)012<1169: TSMWOT $>2.0 . \mathrm{CO} ; 2$.

McDonagh, E., and Coauthors, 2015: Continuous estimate of Atlantic oceanic freshwater flux at $26.58^{\circ}$ N. J. Climate, 28, 8888-8906, https://doi.org/10.1175/JCLI-D-14-00519.1.

McIntosh, P. C., and T. J. McDougall, 1996: Isopycnal averaging and the residual mean circulation. J. Phys. Oceanogr., 26, 1655-1660, https://doi.org/10.1175/1520-0485(1996)026<1655: IAATRM $>2.0 . \mathrm{CO} ; 2$.

Mertens, C., M. Rhein, M. Walter, C. W. Boning, E. Behrens, D. Kieke, R. Steinfeldt, and U. Stober, 2014: Circulation and transports in the Newfoundland Basin, western subpolar North Atlantic. J. Geophys. Res. Oceans, 119, 7772-7793, https://doi.org/10.1002/2014JC010019.

Müller, P., and C. Garrett, 2002: From stirring to mixing in a stratified ocean. Oceanography, 15 (3), 12-19, https://doi.org/ 10.5670/oceanog.2002.10.

Pickart, R. S., and M. A. Spall, 2007: Impact of Labrador Sea convection on the North Atlantic meridional overturning circulation. J. Phys. Oceanogr., 37, 2207-2227, https://doi.org/ 10.1175/JPO3178.1.

,-- , and J. R. N. Lazier, 1997: Mid-depth ventilation in the western boundary current system of the sub-polar gyre. DeepSea Res. I, 44, 1025-1054, https://doi.org/10.1016/S0967-0637 (96)00122-7.

, D. T. Torres, and R. A. Clarke, 2002: Hydrography of the Labrador Sea during active convection. J. Phys. Oceanogr., 32, 428-457, https://doi.org/10.1175/1520-0485(2002)032<0428: HOTLSD $>2.0 . \mathrm{CO} ; 2$.

F. Straneo, and G. W. K. Moore, 2003a: Is Labrador Sea Water formed in the Irminger Basin? Deep-Sea Res. I, 50, 23-52, https://doi.org/10.1016/S0967-0637(02)00134-6.

—, M. A. Spall, M. H. Ribergaard, G. W. K. Moore, and R. F. Milliff, 2003b: Deep convection in the Irminger Sea forced by the Greenland tip jet. Nature, 424, 152-156, https://doi.org/ 10.1038/nature01729.

— D. J. Torres, and P. S. Fratantoni, 2005: The East Greenland spill jet. J. Phys. Oceanogr., 35, 1037-1053, https://doi.org/ 10.1175/JPO2734.1.

Rhein, M., and Coauthors, 2002: Labrador Sea Water: Pathways, CFC inventory, and formation rates. J. Phys. Oceanogr., 32, 648-665, https://doi.org/10.1175/1520-0485(2002)032<0648: LSWPCI $>2.0 . \mathrm{CO} ; 2$.

Rosmond, T., J. Teixeira, M. Peng, T. Hogan, and R. Pauley, 2002: Navy Operational Global Atmospheric Prediction System (NOGAPS): Forcing for ocean models. Oceanography, 15 (1), 99-108, https://doi.org/10.5670/oceanog.2002.40.

Rousset, C., M.-N. Houssais, and E. P. Chassignet, 2009: A multimodel study of the restratification phase in an idealized convection basin. Ocean Modell., 26, 115-133, https://doi.org/ 10.1016/j.ocemod.2008.08.005.

Saunders, P. M., 2001: The dense northern overflows. Ocean Circulation and Climate, G. Siedler, J. Church, and J. Gould, Eds., Academic Press, 401-417. 
Schmidtko, S., G. C. Johnson, and J. M. Lyman, 2013: MIMOC: A global monthly isopycnal upper-ocean climatology with mixed layers. J. Geophys. Res. Oceans, 118, 1658-1672, https://doi.org/10.1002/jgrc.20122.

Schott, F. A., L. Stramma, R. Zantopp, M. Dengler, J. Fischer, and M. Wibaux, 2004: Circulation and deep water export at the western exit of the subpolar North Atlantic. J. Phys. Oceanogr., 34, 817-843, https://doi.org/10.1175/1520-0485(2004)034<0817: CADEAT $>2.0 . \mathrm{CO} ; 2$.

- J. Fischer, M. Dengler, and R. Zantopp, 2006: Variability of the deep western boundary current east of the Grand Banks. Geophys. Res. Lett., 33, L21S07, https://doi.org/10.1029/ 2006GL026563.

Semtner, A. J., 1976: A model for the thermodynamic growth of sea ice in numerical investigations of climate. J. Phys. Oceanogr., 6, 379-389, https://doi.org/10.1175/1520-0485(1976)006<0379: AMFTTG $>2.0 . \mathrm{CO} ; 2$.

Smith, L. T., E. P. Chassignet, and R. Bleck, 2000: The impact of lateral boundary conditions and horizontal resolution on North Atlantic water mass transformations and pathways in an isopycnic coordinate ocean model. J. Phys. Oceanogr., 30, 137-159, https://doi.org/10.1175/1520-0485(2000)030<0137: TIOLBC $>2.0 . \mathrm{CO} ; 2$.

Speer, K. G., and E. Tziperman, 1992: Rates of water mass formation in the North Atlantic Ocean. J. Phys. Oceanogr., 22, 93-104, https:// doi.org/10.1175/1520-0485(1992)022<0093:ROWMFI >2.0.CO;2.

_, H. J. Isemer, and A. Biastoch, 1995: Water mass formation from revised COADS data. J. Phys. Oceanogr., 25, 2444-2457, https:// doi.org/10.1175/1520-0485(1995)025<2444:WMFFRC >2.0.CO;2.

Talley, L. D., and M. S. McCartney, 1982: Distribution and circulation of Labrador Sea Water. J. Phys. Oceanogr., 12, 1189-1205, https:// doi.org/10.1175/1520-0485(1982)012<1189:DACOLS > 2.0.CO;2.

Thomas, L., J. Taylor, R. Ferrari, and T. Joyce, 2013: Symmetric instability in the Gulf Stream. Deep-Sea Res. II, 91, 96-110, https://doi.org/10.1016/j.dsr2.2013.02.025.
Treguier, A. M., S. Theetten, E. P. Chassignet, T. Penduff, R. Smith, L. Talley, J. O. Beisman, and C. Boening, 2005: The North Atlantic subpolar gyre in four high-resolution models. J. Phys. Oceanogr., 35, 757-774, https://doi.org/10.1175/JPO2720.1.

Uppala, S. M., and Coauthors, 2005: The ERA-40 Re-Analysis. Quart. J. Roy. Meteor. Soc., 131, 2961-3012, https://doi.org/ 10.1256/qj.04.176.

von Appen, W.-J., and Coauthors, 2014: The East Greenland Spill Jet as an important component of the Atlantic meridional overturning circulation. Deep-Sea Res. I, 92, 75-84, https://doi.org/ 10.1016/j.dsr.2014.06.002.

Walin, G., 1982: On the relation between sea-surface heat flow and thermal circulation in the ocean. Tellus, 34, 187-195, https:// doi.org/10.3402/tellusa.v34i2.10801.

Walter, M., C. Mertens, and M. Rhein, 2005: Mixing estimates from a large-scale hydro-graphic survey in the North Atlantic. Geophys. Res. Lett., 32, L13605, https://doi.org/10.1029/ 2005 GL022471.

Xu, X., W. J. Schmitz Jr., H. E. Hurlburt, P. J. Hogan, and E. P. Chassignet, 2010: Transport of Nordic seas overflow water into and within the Irminger Sea: An eddy-resolving simulation and observations. J. Geophys. Res., 115, C12048, https://doi.org/10.1029/2010JC006351.

_ , P. B. Rhines, E. P. Chassignet, and W. J. Schmitz Jr., 2015: Spreading of the Denmark Strait overflow water in the western subpolar North Atlantic: Insights from eddy-resolving simulations with a passive tracer. J. Phys. Oceanogr., 45, 29132932, https://doi.org/10.1175/JPO-D-14-0179.1.

$\longrightarrow, \ldots$, and $\longrightarrow, 2016$ : Temperature-salinity structure of the North Atlantic circulation and associated heat and freshwater transports. J. Climate, 29, 7723-7742, https://doi.org/10.1175/ JCLI-D-15-0798.1.

Yashayaev, I., 2007: Hydrographic changes in the Labrador Sea, 1960-2005. Prog. Oceanogr., 73, 242-276, https://doi.org/10.1016/ j.pocean.2007.04.015. 